\title{
Article \\ $\sigma$-Holes on Transition Metal Nanoclusters and Their Influence on the Local Lewis Acidity
}

\author{
Joakim H. Stenlid ${ }^{1}{ }^{(\mathbb{D}}$, Adam Johannes Johansson ${ }^{2}$ and Tore Brinck ${ }^{1, *}$ \\ 1 Applied Physical Chemistry, School of Chemical Science and Engineering, \\ KTH Royal Institute of Technology, Teknikringen 36, SE-100 44 Stockholm, Sweden; kjhs@kth.se \\ 2 Swedish Nuclear Fuel and Waste Management Company (SKB), Evenemangsgatan 13, Box 3091, \\ SE-169 03 Solna, Sweden; johannes.johansson@skb.se \\ * Correspondence: tore@kth.se; Tel.: +46-8-790-8210
}

Academic Editors: Peter Politzer and Jane S. Murray

Received: 10 June 2017; Accepted: 11 July 2017; Published: 14 July 2017

\begin{abstract}
Understanding the molecular interaction behavior of transition metal nanoclusters lies at the heart of their efficient use in, e.g., heterogeneous catalysis, medical therapy and solar energy harvesting. For this purpose, we have evaluated the applicability of the surface electrostatic potential $\left[V_{S}(\mathbf{r})\right]$ and the local surface electron attachment energy $\left[E_{S}(\mathbf{r})\right]$ properties for characterizing the local Lewis acidity of a series of low-energy $\mathrm{TM}_{13}$ transition metal nanoclusters $(\mathrm{TM}=\mathrm{Au}, \mathrm{Cu}, \mathrm{Ru}, \mathrm{Rh}, \mathrm{Pd}$, $\mathrm{Ir}, \mathrm{Pt}, \mathrm{Co})$, including also $\mathrm{Pt}_{7} \mathrm{Cu}_{6}$. The clusters have been studied using hybrid Kohn-Sham density functional theory (DFT) calculations. The $V_{\mathrm{S}}(\mathbf{r})$ and $E_{\mathrm{S}}(\mathbf{r})$, evaluated at 0.001 a.u. isodensity contours, are used to analyze the interactions with $\mathrm{H}_{2} \mathrm{O}$. We find that the maxima of $V_{\mathrm{S}}(\mathbf{r}), \sigma$-holes, are either localized or diffuse. This is rationalized in terms of the nanocluster geometry and occupation of the clusters's, $p$ and $d$ valence orbitals. Our findings motivate a new scheme for characterizing $\sigma$-holes as $\sigma_{s}$ (diffuse), $\sigma_{p}$ (localized) or $\sigma_{d}$ (localized) depending on their electronic origin. The positions of the maxima in $V_{S}(\mathbf{r})$ (and minima in $E_{S}(\mathbf{r})$ ) are found to coincide with O-down adsorption sites of $\mathrm{H}_{2} \mathrm{O}$, whereas minima in $V_{\mathrm{S}}(\mathbf{r})$ leads to H-down adsorption. Linear relationships between $V_{\mathrm{S} \text {, max }}$ (and $E_{S, \min }$ ) and $\mathrm{H}_{2} \mathrm{O}$ interaction energies are further discussed.
\end{abstract}

Keywords: $\sigma$-holes; surface electrostatic potential; local electron attachment energy; $\mathrm{H}_{2} \mathrm{O}$ interactions; transition metal nanoparticles; Lewis acidity

\section{Introduction}

Surface maxima in the molecular electrostatic potential $\left(V_{S, \max }\right)$ along the lateral extensions of intramolecular bonds are known as $\sigma$-holes [1]. These have been widely used to rationalize molecular interaction behavior and reactivity [2]. In the present contribution we introduce new categories of $\sigma$-holes based on the electronic origin of the $V_{\mathrm{S}, \max }$; if the $V_{\mathrm{S}, \max }$ arises primarily as a consequence of electron deficiencies in the valence s-orbitals of the compound, we shall denote it an $\sigma_{S}$-hole. Similarly, $V_{S, \max }$ originating from deficiencies in the $p$ - or $d$-orbitals will be referred to as $\sigma_{p}$ - or $\sigma_{d}$-holes. Mixtures of these exist. The new categorization is herein motivated by a detailed analysis of transition metal (TM) nanoclusters, and arises naturally from the occurrence of diffuse (non-directional) or localized (directional) $\sigma$-hole on the TM compounds. With some few exceptions, e.g., refs. [3-7], TM compounds have not commonly been characterized by surface electrostatic potential maps. We will here show that $\sigma$-holes are useful guides also for TM interactions with clear similarities to halogen or hydrogen bonding.

Representative examples of $\sigma_{s^{-}}$and $\sigma_{p}$-holes can be found on hydrogen and singly coordinated halogen $(\mathrm{X}=\mathrm{Cl}, \mathrm{Br}$ and $\mathrm{I})$ atoms participating in hydrogen and halogen bonding. The $V_{\mathrm{S}, \max }$ of the hydrogen atom of e.g., HF (Figure 1) arises because, upon formation of the covalent H-F bond, 
electron density is relocated from the non-bonding sides of the atoms to the bonding region between them. The large difference in electronegativity between $\mathrm{H}$ and $\mathrm{F}$ further leads to a strong polarization towards $\mathrm{F}$ in the bonding $\sigma$-orbital. The $\sigma^{*}$-orbital is, on the other hand, highly polarized towards $\mathrm{H}$ but because it is unoccupied it will not compensate for the polarization of the $\sigma$-orbital. Consequently, the occupation of the $\sigma$-orbitals effectively results in a substantial electron deficiency on $\mathrm{H}$. This is manifested by a large positive electrostatic potential at the $\mathrm{H}$ atom-an $\sigma_{s}$-hole since it originates in the hydrogen s-orbital occupation. Simultaneously a negative electrostatic potential is built up on F. Due to the spherical symmetry of the $\mathrm{H} 1 s$ orbital, the corresponding $\sigma_{s}$-hole is diffused over the entire $\mathrm{H}$ end of the molecule. This explains the weak directionality of $\mathrm{H}$-bond interactions, which often deviate significantly from $180^{\circ}$ [8]. In the following we will show that common features of $\sigma_{S}$-holes are their diffuse and non-directional character. $V_{\mathrm{S} \text {, max }}$ have also been used to rationalize the formation of non-covalent bonds between halogen atoms and electron donating compounds, i.e., halogen bonds $[9,10]$. In contrast to hydrogen bonds, halogen bonds are highly directional. This can be attributed to the partial occupation of the valence $p$ - rather than s-orbitals. Figure 1 includes the example of the $\mathrm{I}_{2}$ molecule. The intramolecular bonding in $\mathrm{I}_{2}$ is, by and large, the consequence of the mixing of two I $5 p_{\mathrm{z}}$ orbitals, leading to a $\sigma_{p z}$-bond where the $\sigma_{p z}$-orbital is occupied and the $\sigma^{*} p z$-orbital is unoccupied. Similarly to HF, this gives rise to electron deficiencies in the lateral extensions of the I-I bond, with two corresponding $V_{S \text {, max }}$ at the edges of the $\sigma$-framework. Using the principles for $\sigma$-hole categorization from above, the $V_{\mathrm{S}, \max }$ of halogen atoms should be denoted $\sigma_{p}$-holes due to the $p$-origin of the hole. Owing to the largely directional character of the $p_{\mathrm{z}}$ orbitals, the $\sigma_{p}$-holes are highly localized in the direction of the $\sigma$-bond. Consequently, the halogen bond interactions are, in contrast to hydrogen bonds, found to be directional with A $\cdots$ X-R angles close to $180^{\circ}$ [8].

For TM compounds, we analogously find that areas of high electrostatic potential are sometimes localized along the extension of TM-TM bonds. In addition, multiple $V_{\mathrm{S} \text {, max }}$ may arise on the same atom corresponding to up to one $\sigma$-hole per TM-TM bond. This can be traced to the partially occupied $d$-orbitals of the TM compound and will thus be called $\sigma_{d}$-holes. The square planar $\mathrm{Pt}_{4}$ cluster of Figure 1 can be taken as an example. Pt has a $5 d^{9} 6 s^{1}$ valence configuration and accordingly the local electron deficiencies of $\mathrm{Pt}_{4}$ are a consequence of the redistribution of both $s$ - and $d$-orbital densities (the minor mixing of $6 p$-orbitals is here neglected for the sake of simplicity). The s-deficiencies promote the creation of areas of high electrostatic potential on the corners of $\mathrm{Pt}_{4}$. The corners do, however, not correspond to maxima as the $V_{\mathrm{S}}(\mathbf{r})$ profile is also affected by the $d$-occupation. This promotes the formation of $V_{\mathrm{S}, \max }$ at the extension of the $\sigma_{d}$-bonds created by the overlap of $5 d_{\mathrm{z} 2}$ and $5 d_{\mathrm{x} 2-\mathrm{y} 2}$ orbitals, i.e., at each side of the corners of the $\mathrm{Pt}_{4}$ square structure. These $V_{S, \max }$ are thus best referred to as $\sigma_{d}$-holes. The $\sigma_{p}$ - and $\sigma_{d}$-holes have in common that they are highly localized along the direction of the intramolecular bond.

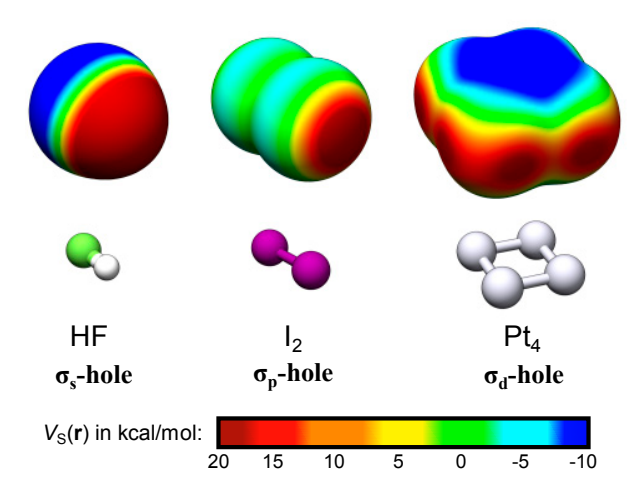

Figure 1. The $\sigma_{s^{-}}, \sigma_{p^{-}}$and $\sigma_{d}$-holes are exemplified by the electrostatic potential profiles, $V_{S}(\mathbf{r})$, of HF, $\mathrm{I}_{2}$ and $\mathrm{Pt}_{4}$. The $V_{\mathrm{S}}(\mathbf{r})$ was evaluated on the 0.001 a.u. isodensity contour at structures characterized at the PBE0/def2-TZVPP//def2-SV(P) level of theory [11,12] using the Turbomole 6.4 package [13]. Note that the $V_{\mathrm{S} \text {,max }}$ of $\mathrm{Pt}_{4}$ are not located at the corners but at the extension of the bonds (dark red areas). 
In the present work, we shall investigate the presence and absence of the various kinds of $\sigma$-holes on a series of neutral, low-energy $\mathrm{TM}_{13}$ nanoclusters [14-23]. The nanoclusters comprise the mixed elemental $\mathrm{Pt}_{7} \mathrm{Cu}_{6}$ nanocluster as well as the $\mathrm{Ir}_{13}, \mathrm{Pt}_{13}, \mathrm{Au}_{13}, \mathrm{Pd}_{13}, \mathrm{Rh}_{13}, \mathrm{Ru}_{13}, \mathrm{Cu}_{13}$ and $\mathrm{Co}_{13}$ clusters. Nanomaterial based on TM elements are essential components in a range of emergent and established applications including heterogeneous catalysis, medical therapy and solar energy harvesting [24-31], and in order to design and efficiently utilize these materials, a thorough understanding of their interaction behavior with ambient molecules is necessary [32]. In line with this, we have recently suggested that the electrostatic potential profile, $\left[V_{S}(\mathbf{r})\right]$, obtained at contours of constant electron density, can be used to rationalize the catalytic activity of Au nanoparticles (NPs) of 0.5-3 nm sizes [3]. We have also found that, besides Au NPs, $V_{S}(\mathbf{r})$ can be used to characterize the interaction behavior of $\mathrm{NPs}$ of the other $d^{10} s^{1}$-valence elements, i.e., $\mathrm{Ag}$ and $\mathrm{Cu}[4,5]$. By comparing the adsorption behavior of the $\mathrm{H}_{2} \mathrm{O}$ probe molecule with the surface electrostatic potential profiles (computed with hybrid KS-DFT) of the abovementioned group 8-11 $\mathrm{TM}_{13}$ nanoclusters, we will demonstrate that the positions of $V_{\mathrm{S}, \max }\left(\sigma\right.$-holes) and $V_{\mathrm{S} \text {, min }}$ largely dictate the position and adsorption mode of $\mathrm{H}_{2} \mathrm{O}$. In addition, we will compare the information obtained by the $V_{\mathrm{S}}(\mathbf{r})$ to that of the local electron attachment energy, $E(\mathbf{r})$ (vide infra) [33]. This quantity contains information, not only about the electrostatic contribution to an interaction, but also on the charge-transfer-polarization effects. When evaluated on an isodensity surface, $E(\mathbf{r})$ is denoted $E_{S}(\mathbf{r})$ and has, similar to $V_{S}(\mathbf{r})$, been found to be a useful guide in the analysis of $\mathrm{Au}, \mathrm{Ag}$ and $\mathrm{Cu}$ nanocluster interactions, [4] but also for characterizing electrophilicity and the Lewis acidity of organic molecules [33,34].

\section{Theory}

The electrostatic potential $[V(\mathbf{r})]$ at a position $\mathbf{r}$ of a polyatomic system can be obtained by experimental $[35,36]$ as well as computational methods. $V(\mathbf{r})$ is rigorously defined via [2]

$$
V(\mathbf{r})=\sum_{A} \frac{\mathrm{Z}_{A}}{\left|\mathrm{R}_{A}-\mathbf{r}\right|}-\int \frac{\rho\left(\mathbf{r}^{\prime}\right) \mathrm{d} \mathbf{r}^{\prime}}{\left|\mathbf{r}^{\prime}-\mathbf{r}\right|}
$$

$\mathrm{Z}_{A}$ and $\mathrm{R}_{A}$ are the charge and spatial position of $A$, the nuclei of the system, while $\rho\left(\mathbf{r}^{\prime}\right)$ is the total electronic density at position $\mathbf{r}^{\prime}$. For the study of interaction properties, $V(\mathbf{r})$ is commonly evaluated on an isodensity contour surface of 0.001 a.u. and denoted $V_{S}(\mathbf{r})$. Maxima in $V_{\mathrm{S}}(\mathbf{r})$, i.e., $V_{\mathrm{S} \text {, max }}$, indicate sites susceptible to interactions with nucleophiles (Lewis basis), e.g., the $\mathrm{H}_{2} \mathrm{O}$ molecule when interacting via its oxygen electron lone pairs. Correspondingly, minima in $V_{\mathrm{S}}(\mathbf{r})$, i.e., $V_{\mathrm{S}, \min }$, indicate sites prone to interaction with electrophiles (Lewis acids). $V_{S}(\mathbf{r})$ has been employed extensively in the study of molecular interactions including hydrogen and halogen bonding, biomolecular recognition interaction, estimations of $\mathrm{pK}_{\mathrm{A}}$ and molecular reactivity [2].

Whereas $V(\mathbf{r})$ reflects the electrostatic character of an interaction, the local electron attachment energy, $E(\mathbf{r})]$, is able to capture both the electrostatics and charge-transfer-polarization components of an interaction (see below) and can thus be used complementary to $V(\mathbf{r})$. In the general case, $E(\mathbf{r})=E^{E 0}(\mathbf{r})$ is obtained by summarizing overall virtual (spin) orbitals from LUMO up to a given cut-off level, $E_{0}$, via [33]

$$
E^{E_{0}}(\mathbf{r})=\frac{\sum_{i=\mathrm{LUMO}}^{\varepsilon_{i}<E_{0}}\left(\varepsilon_{i}-E_{0}\right) \rho_{i}(\mathbf{r})}{\rho(\mathbf{r})} .
$$

Here $\rho_{i}(\mathbf{r})$ and $\varepsilon_{i}$ are the local density and eigenvalue of the $i$ th virtual orbital. Within the generalized Kohn-Sham DFT (GKSDFT), it follows directly from Janak's theorem ( $\mathrm{d} E_{\text {tot }} / \mathrm{d} n_{\mathrm{i}}=\varepsilon_{i}$, $E_{\text {tot }}=$ total energy) [37], that $E_{0}=0$ is a sensible choice. This is due to the fact that, if we assume a frozen orbital picture, only orbitals with $\varepsilon_{i}<0$ will bind an electron. Hence, we define $E(\mathbf{r})=E^{E 0=0}(\mathbf{r})$ as

$$
E(\mathbf{r})=\frac{\sum_{i=\mathrm{LUMO}}^{\varepsilon_{i}<0} \varepsilon_{i} \rho_{i}(\mathbf{r})}{\rho(\mathbf{r})} .
$$


Equation (3) bears resemblance to the local electron affinity property $\left[E A_{\mathrm{L}}(\mathbf{r})\right]$ of Clark and co-workers [38,39]; the two quantities differ in the use of the $E_{0}$ cut-off in $E(\mathbf{r})$, whereas no cut-off is used in the evaluation of $E A_{\mathrm{L}}(\mathbf{r})$, and in the normalization by the total virtual density in $E A_{\mathrm{L}}(\mathbf{r})$, while $E(\mathbf{r})$ is normalized by the total occupied electron density. Besides the purely physical arguments for only accounting for bound one-electron states (i.e., $\left.\varepsilon_{i}<0\right)$ in $E(\mathbf{r})$, the introduction of the energy offset greatly reduces the sensitivity of the property on the basis set size. Furthermore, the use of the unoccupied density in the denominator when evaluating $E A_{\mathrm{L}}(\mathbf{r})$ incorrectly leads to the assignment of high reactivity to regions of low virtual density.

The $E(\mathbf{r})$ quantity can, in analogy to its nucleophilic counterpart $\bar{I}(\mathbf{r})$ (the average local ionization energy $[40,41])$, be decomposed into contributions from the electrostatic potential, the kinetic energy density $t_{\mathrm{i}}(\mathbf{r})$ and the exchange-correlation potential $\left[V_{\mathrm{XC}}(\mathbf{r})\right]$ by $[33,42]$

$$
E(\mathbf{r})=\frac{1}{\rho(\mathbf{r})}\left[\sum_{i=\mathrm{LUMO}}^{\varepsilon_{i}<0} t_{i}(\mathbf{r})-V(\mathbf{r}) \sum_{i=\mathrm{LUMO}}^{\varepsilon_{i}<0} \rho_{i}(\mathbf{r})+V_{\mathrm{XC}}(\mathbf{r}) \sum_{i=\mathrm{LUMO}}^{\varepsilon_{i}<0} \rho_{i}(\mathbf{r})\right],
$$

where $t_{\mathrm{i}}(\mathbf{r})=-\frac{1}{2} \psi_{\mathrm{i}}^{*}(\mathbf{r}) \nabla^{2} \psi_{\mathrm{i}}(\mathbf{r})$. In Equation (4), the $t_{\mathrm{i}}(\mathbf{r})$ term is the only one that directly depends on the functional forms of the virtual orbitals. This term gives the charge-transfer-polarization contribution to the $E(\mathbf{r})$ quantity, whereas, when $E(\mathbf{r})$ is determined on an isodensity contour (i.e., $\left.E_{\mathrm{S}}(\mathbf{r})\right), V_{\mathrm{XC}}(\mathbf{r})$ is approximately constant [33]. Minima in $E_{\mathrm{S}}(\mathbf{r})$ are denoted $E_{\mathrm{S}, \min }$ and can be used to rationalize the electrophilic (Lewis acidic) behavior of $\mathrm{Au}, \mathrm{Ag}$, and $\mathrm{Cu}$ nanoparticles [4], as well as for characterizing halogen bonding and the local reactivity of aromatic and conjugated electrophilic organic molecules [33,34].

\section{Computational Details}

The TM nanoclusters were studied in vacuo using hydrid DFT calculations via the PBE0 exchange-correlation functional [11], augmented with Grimme's D3 dispersion corrections [43], and employing Becke-Johnson damping [44]. The initial geometries for the $\mathrm{Au}_{13}, \mathrm{Cu}_{13}, \mathrm{Pt}_{13}, \mathrm{Pt}_{7} \mathrm{Cu}_{6}$, $\mathrm{Pd}_{13}, \mathrm{Co}_{13}, \mathrm{Ir}_{13}, \mathrm{Rh}_{13}$, and $\mathrm{Ru}_{13} \mathrm{TM}$ nanoclusters were taken from documented low-energy structures (Figure 2) [14-23]. These were reoptimized under symmetry constraints in the Turbomole 6.4 software package [13] using the Def2-TVZP basis set; the Def2 basis set family of Ahlrichs and co-workers [12] employs effective core potentials (ECPs) for the $4 \mathrm{~d}$ and $5 \mathrm{~d}$, but not for the $3 \mathrm{~d}$ metals. The optimizations were repeated for all spin-states going from singlet (or doublet) up to tridecatet (or dodecatet). $\mathrm{Co}_{13}$ is an exception where a $2 \mathrm{~S}+1=28$ spin-state has been reported as the ground state, which could be corroborated herein [14,18]. The identified ground states (lowest-energy spin-states), reported in Table 1, of all clusters were used in the continued study; see the discussion in the supplementary material for details (Section S1 and Table S2). Evaluation of the $V_{\mathrm{S}}(\mathbf{r})$ and $E_{\mathrm{S}}(\mathbf{r})$ quantities were performed at the 0.001 a.u. isodensity contours employing the in-house HS95 program (T. Brinck) and visualized using the UCSF Chimera software [45]. The evaluations were based on Kohn-Sham orbitals obtained from calculations performed in the Gaussian 09 program suite [46] using the Def2-TZVP $(-f g)$ basis set at the optimized geometries. In separate calculations, water molecules were placed O-down at the identified $V_{\mathrm{S}, \max }$ sites of the TM nanoclusters. These structures were optimized with the Orca 3.0.2 program [47] using the RIJCOSX-approximation [48] and the Def2-TVZP basis set. The TM nanocluster atoms were constrained at their previously optimized positions. Final energies were determined using the Def2-TVZPP basis set without the RIJCOSX-approximations in both the Gaussian 09 and Orca 3.0.2 programs, yielding essentially identical results. All final electronic configurations were checked for internal (e.g., symmetry reduction) and external instabilities by the methods discussed in the references $[49,50]$. From the above, site-specific $\mathrm{H}_{2} \mathrm{O}$ interaction energies $\left(\Delta E_{\text {int }}\right)$ could be determined by

$$
\Delta E_{\mathrm{int}}=E_{\mathrm{TM}-\mathrm{H} 2 \mathrm{O}}-\left(E_{\mathrm{TM}}+E_{\mathrm{H} 2 \mathrm{O}}\right),
$$


where $E_{\mathrm{TM}-\mathrm{H} 2 \mathrm{O}}, E_{\mathrm{TM}}$, and $E_{\mathrm{H} 2 \mathrm{O}}$ correspond to the electronic energies of the $\mathrm{H}_{2} \mathrm{O}-\mathrm{TM}$ nanocluster adduct, the bare TM nanocluster, and free $\mathrm{H}_{2} \mathrm{O}$ molecule, respectively. Note that neither zero-point nor any other thermochemical correction has been included in the interaction energy calculations. The valence $s^{-}, p$ - and $d$-occupations of the TM nanoclusters were studied by natural bond orbital (NBO) analysis using the NBO version 3.1 implementation in Gaussian 09 [51].

$\mathrm{Au}_{13}$
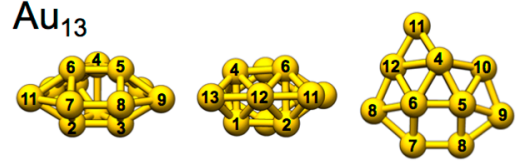

$\mathrm{Cu}_{13}$
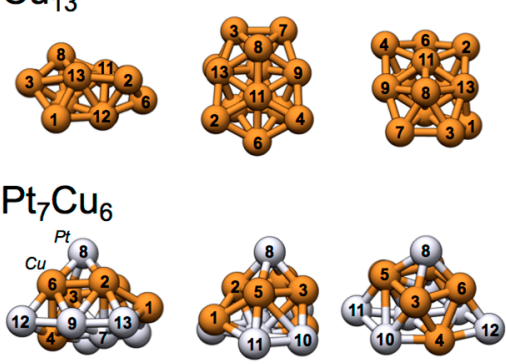
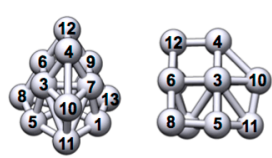

$\mathrm{Pd}_{13}$
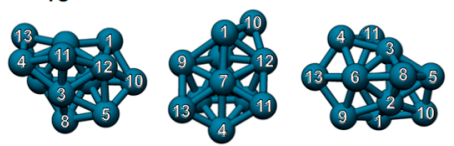

$\mathrm{Ru}_{13}$
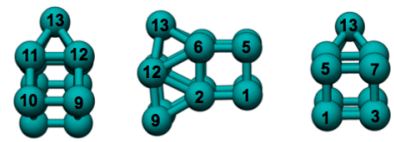
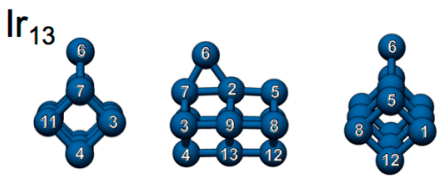

$\mathrm{Rh}_{13}$
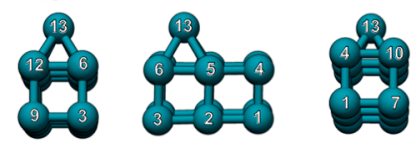

$\mathrm{Co}_{13}$
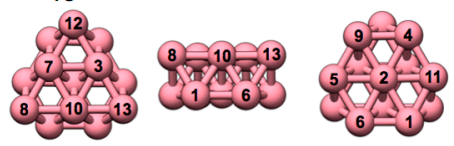

Figure 2. Structures and atomic indexation of the $\mathrm{TM}_{13}$ nanoclusters shown from different angles.

Table 1. $\mathrm{TM}_{13}$ nanocluster Schönflies symmetry group (Sym), ground-state spin multiplicity $(2 \mathrm{~S}+1)$, and the number of unique atom binding sites (AS), as well as unique $V_{\mathrm{S} \text {, max }}$ sites (VS) and $E_{\mathrm{S} \text {, min }}$ sites (ES) identified on each cluster. Included are also the atom average valence $s^{-}, d$ - and $p$-occupations $(s-, d$ - and $p$-occ) as determined by NBO analysis [51].

\begin{tabular}{|c|c|c|c|c|c|c|c|c|}
\hline & Sym & $(2 S+1)$ & AS & VS & ES & $s$-occ ${ }^{1}$ & $d$-occ ${ }^{1}$ & $p$-occ ${ }^{1}$ \\
\hline $\mathrm{Au}_{13}$ & $C_{S}$ & 2 & 10 & 10 & 9 & 0.73 & 9.90 & 0.38 \\
\hline $\mathrm{Cu}_{13}$ & $C_{2}$ & 2 & 7 & 6 & 6 & 0.63 & 9.94 & 0.44 \\
\hline $\mathrm{Pt}_{13}$ & $C_{S}$ & 3 & 7 & 15 & 15 & 0.61 & 9.08 & 0.32 \\
\hline $\mathrm{Pt}_{7} \mathrm{Cu}_{6}$ & $C_{1}$ & 3 & 13 & 12 & 11 & $0.56^{2}$ & $9.56^{2}$ & $0.34^{2}$ \\
\hline $\mathrm{Pd}_{13}$ & $C_{2}$ & 9 & 7 & 7 & 8 & 0.37 & 9.34 & 0.29 \\
\hline $\mathrm{Co}_{13}$ & $C_{3}$ & 28 & 4 & 4 & 3 & 0.65 & 7.82 & 0.52 \\
\hline $\mathrm{Rh}_{13}$ & $C_{S}$ & $2^{3}$ & 7 & 7 & 14 & 0.43 & 8.30 & 0.27 \\
\hline $\mathrm{Ir}_{13}$ & $C_{S}$ & 4 & 10 & 17 & 15 & 0.67 & 7.97 & 0.37 \\
\hline $\mathrm{Ru}_{13}$ & $C_{S}$ & 13 & 7 & 6 & 9 & 0.46 & 7.22 & 0.34 \\
\hline
\end{tabular}

${ }^{1}$ In case the total valence occupation does not fully amount to the total number of valence electrons, the remaining electron density is spread over the +1 super-valence $s-, p-, d-$, and $f$-orbitals. ${ }^{2}$ Average valence occupation $\mathrm{Pt}(s: 0.71$, $d: 9.25, p: 0.28)$ and $\mathrm{Cu}(s: 0.40, d: 9.92, p: 0.41) .{ }^{3}$ The $2 \mathrm{~S}+1=10$ state is almost degenerate, see supplementary material (Section S3 and Table S5).

\section{Results and Discussion}

In this part, we will examine the different kinds of $\sigma$-holes that emerge on TM nanoclusters, when to expect them and how these influence the local Lewis acidity (and basicity) of the cluster.

\subsection{Exemplifying the Origin of the $T M \sigma_{s}$-Holes and $\sigma_{d}$-Holes-The $T M_{2}$ and $T M_{8}$ of $I r$, Pt and $A u$}

The valence occupation of the neutral compounds of the elements of the Cu-group (group 11) is approximately $d^{10} s^{1}$. Thus, their $V_{S}(\mathbf{r})$ profiles can be understood in terms of the $p$-mixed $s$-occupation [3,4]. For the TM elements to the left of the Cu-group in the periodic table, the occupation of the valence states is changed; especially the $d$-orbitals are monotonically emptied and consequently a variety of different spin-states become attainable. This affects the electrostatic potential profile of the corresponding TM NPs directly, by changing the electronic configuration, and indirectly by altering 
the favored geometrical structure [14]. The cubic octamers of Au, Pt and Ir are used as examples below to demonstrate the variations in the $V_{\mathrm{S}}(\mathbf{r})$ profile with the $d$-occupation (Figure 3 ).

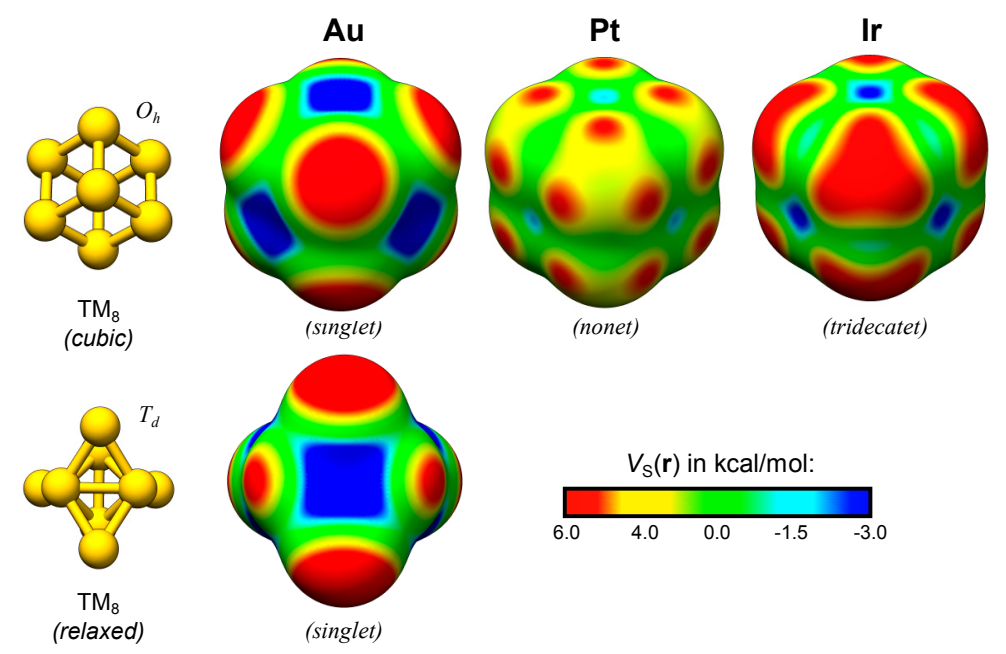

Figure 3. $\mathrm{Au}, \mathrm{Pt}$ and $\mathrm{Ir} \mathrm{TM}_{2}$ and $\mathrm{TM}_{8}$ nanoclusters optimized at the PBE0/def2-SV(P) level of theory [11,12] using the Turbomole 6.4 software package [13]. The electrostatic potential profiles, $V_{\mathrm{S}}(\mathbf{r})$, were evaluated at the 0.001 a.u. isodensity surface at the PBE0/def2-TZVPP level of theory. See the supplementary material for further details (Section S4 and Table S1).

An NBO analysis of the cubic $\mathrm{Au}_{8}$ (singlet) cluster indeed suggests that it has approximately fully occupied $5 d$-orbitals and partially filled $6 s$-orbitals (NBO valence occupation: $5 d^{9.92} 6 s^{0.86} 6 p^{0.22}$ ). As expected, the cubic $\mathrm{Au}_{8}$ (singlet) display $V_{\mathrm{S}, \max }$ at the corner sites. Although the cubic structure is not stable for $\mathrm{Au}_{8}$, it relaxes to a structure with $T_{d}$ symmetry (Figure 3) that still display $V_{\mathrm{S}, \max }$ at corner sites. It is worth noting at this point that the location of the $\sigma_{s}$-holes of $\mathrm{Au}_{8}$ at positions deviant from the extensions of the TM-TM bonds suggest that they may not be proper $\sigma$-holes; the $V_{\mathrm{S} \text {, max }}$ are positioned at angles deviant from straight $\left(180^{\circ}\right)$ or right $\left(90^{\circ}\right)$ with respect to the $\sigma$-bonds of the cluster. This may instead motivate the coining of the term pseudo $\delta$-hole (in analogy with the pseudo $\pi$-holes of planar structures [52]). However, we argue that the introduction of a pseudo $\delta$-hole is unnecessary in this case and that the proper notation for the $V_{\mathrm{S}, \max }$ of $\mathrm{Au}_{8}$ (and similarly, $V_{\mathrm{S}, \max }$ in the continuation of this study) are $\sigma_{s}$-holes, since the positions of the $\sigma$-holes are located at extensions of the joint $\sigma_{s}$-orbital overlap of multiple bonds.

The cubic $O_{h}$ structure is stable for both the $\mathrm{Pt}_{8}$ (nonet) and $\mathrm{Ir}_{8}$ (tridecatet) clusters. For $\mathrm{Pt}_{8}$, $V_{\mathrm{S} \text {, min }}$ are created at the interatomic hollow and bridge sites but there are no $V_{\mathrm{S} \text {,max }}$ on top of the corner atoms. Instead $V_{\mathrm{S} \text {, max }}$ are present at three points at the sides of the corner atoms. These points correspond to the unoccupied positions of an octahedral bonding pattern. The positions of the $V_{\mathrm{S}, \max }$ also coincide with the expected extensions of the $e_{\mathrm{g}}\left(d_{\mathrm{z} 2}\right.$ and $\left.d_{\mathrm{x} 2-\mathrm{y} 2}\right)$ orbitals of such an octahedral symmetry, and hence to the extensions of the $\sigma$-bonds created by the $d$-orbital overlap in the system. These $V_{\mathrm{S} \text {, max }}$ are clear examples of $\sigma_{d}$-holes. We shall find, further on, that the local bonding symmetry is important for the creation of the localized and directional $\sigma_{d}$-holes. For $\mathrm{Pt}_{8}$, the nonet spin-state means that each atom has a magnetic moment of 1 . The partially occupied orbitals of $\mathrm{Pt}_{8}$ are primarily comprised of mixed $d_{\mathrm{x} 2-\mathrm{y} 2}$ - and $d_{\mathrm{z} 2}$-orbitals (NBO valence occupation: $5 d^{9.04} 6 s^{0.75} 6 p^{0.21}$ with $\left.5 d_{\mathrm{xy}}{ }^{1.97} 5 d_{\mathrm{xz}}{ }^{1.97} 5 d_{\mathrm{yz}}{ }^{1.97} 5 d_{\mathrm{x} 2-\mathrm{y} 2}{ }^{1.56} 5 d_{\mathrm{zz}}{ }^{1.56}\right)$. The corresponding average atomic magnetic moment of $\operatorname{Ir}_{8}$ is 1.5 with a clear mixing of $5 d$ orbitals of all different angular momentums, as well as $6 s$ (and $6 p$ ) orbitals in the partially occupied orbitals of highest energy. Due to this electronic configuration, the $V_{S}(\mathbf{r})$ profile is the result of an overlap between, on the one hand, the localized $\sigma_{d}$-holes created by cluster orbitals comprising large $d_{\mathrm{z} 2}$ and $d_{\mathrm{x} 2-\mathrm{y} 2}$ orbital contributions, and, on the other hand, diffuse $\sigma_{d}$-holes that superficially resemble $\sigma_{s}$-holes. The latter originate from $d$-orbitals of other angular momenta than $d_{z 2}$ 
and $d_{\mathrm{x} 2-\mathrm{y} 2}$ (NBO valence occupation: $5 d^{7.97} 6 s^{0.75} 6 p^{0.29}$ with $5 d_{\mathrm{xy}}{ }^{1.65} 5 d_{\mathrm{xz}}{ }^{1.65} 5 d_{\mathrm{yz}}{ }^{1.65} 5 d_{\mathrm{x} 2-\mathrm{y} 2}{ }^{1.51} 5 d_{\mathrm{z} 2}{ }^{1.51}$ ). This gives rise to the triangular shaped $V_{\mathrm{S} \text {, max }}$ at the corner atoms of the cubic $O_{h} \operatorname{Ir}_{8}$ nanocluster. The resulting $\sigma$-holes can be seen as mixed $\sigma_{d}$-holes, or, alternatively, as $\sigma_{d}$-holes masked by pseudo $\sigma_{s}$-holes. We furthermore note that the cubic framework of the $\mathrm{TM}_{8}$ clusters greatly facilitates the analysis of the $d$-orbital angular momentum contributions, which will not be possible for the less symmetric $\mathrm{TM}_{13}$ clusters below.

\subsection{Local Lewis Acidic (and Basic) Characteristics of the $T M_{13}$ Nanoclusters}

The by and large hypothetical $\mathrm{TM}_{8}$ compounds above are illustrative examples but may or may not be representative of nanoclusters active in real applications. For the purpose of evaluating the expected propensity of $\sigma_{s}$ - and $\sigma_{d}$-holes on "real" compounds, we have studied a series of neutrally charged low-energy $\mathrm{TM}_{13}$ nanoclusters, $\mathrm{TM}=\mathrm{Co}, \mathrm{Co}, \mathrm{Au}, \mathrm{Pt}, \mathrm{Pd}, \mathrm{Ir}, \mathrm{Rh}, \mathrm{Ru}$ (Figure 2). In broad terms, the most favorable atomic conformation, magnetic spin-state and electronic valence configuration vary largely for clusters of different TM elements. A common feature is that as the size of the cluster grows, the favorable structure converges towards the compact, close-packed, bulk structure of the corresponding metal [53-56]. However, at the (sub) nanometer scale, it has been established that clusters of e.g., $\mathrm{Rh}, \mathrm{Ru}$, and Ir, adopt an open cubic structure, whereas $3 d$ clusters of $\mathrm{Cu}, \mathrm{Au}$ and $\mathrm{Pd}$ are often found to be compact and possibly disordered [14,57]. There is, furthermore, a preference for $3 d$ clusters to adopt compact atomic configurations while $4 d$ and $5 d$ clusters are generally more open [14]. The $\mathrm{TM}_{13}$ cluster structures of this study will be further discussed below.

Table 1 summarizes the general features of the $\mathrm{TM}_{13}$ nanocluster: their electronic structure, ground-state spin multiplicity, electron valence configuration (as determined by NBO analysis [51]), as well as the number of unique atomic sites, and unique $V_{\mathrm{S} \text {,max }}$ and $E_{\mathrm{S}, \min }$. The $V_{\mathrm{S}}(\mathbf{r})$ and $E_{\mathrm{S}}(\mathbf{r})$ profiles of the nanoclusters are displayed at 0.001 a.u. isodensity contours in Figure 4 . As can be seen in the figure, both $\sigma_{s^{-}}$and $\sigma_{d}$-holes appear on the TM clusters. In general, the $V_{S}(\mathbf{r})$ profiles show areas of high electrostatic potential (i.e., $V_{\mathrm{S}, \max }$ ) on top of atomic sites, whereas low electrostatic potential areas (i.e., $V_{\mathrm{S}, \mathrm{min}}$ ) are located between atoms at bridge or hollow sites. Thus, at a first approach, it is expected that electron-donating molecules (e.g., $\mathrm{H}_{2} \mathrm{O}$ via the $\mathrm{O}$ lone-pairs) preferentially adsorb to the atomic on-top sites, whereas electron-accepting molecules (e.g., $\mathrm{H}_{2} \mathrm{O}$ via the $\mathrm{H}$ atoms) preferentially interact at hollow or bridge sites. $V_{\mathrm{S} \text {, max }}$ of large magnitude are often found at atoms of low coordination. The $E_{S}(\mathbf{r})$ profiles, which can only be used to locate Lewis acidic and not Lewis basic sites, display local minima that largely coincide with the $V_{\mathrm{S}, \max }$. Differences will be discussed in the following sections for each individual nanocluster. The effect of $V_{\mathrm{S}, \max }$ and $E_{\mathrm{S}, \min }$ on the adsorption behavior of $\mathrm{H}_{2} \mathrm{O}$ will also be discussed further below. Figure 5 show the most favorable sites of interaction for all nanoclusters. More details on the $\mathrm{H}_{2} \mathrm{O}-\mathrm{TM}$ interactions are given further below and in the supplementary material (Table S4). 


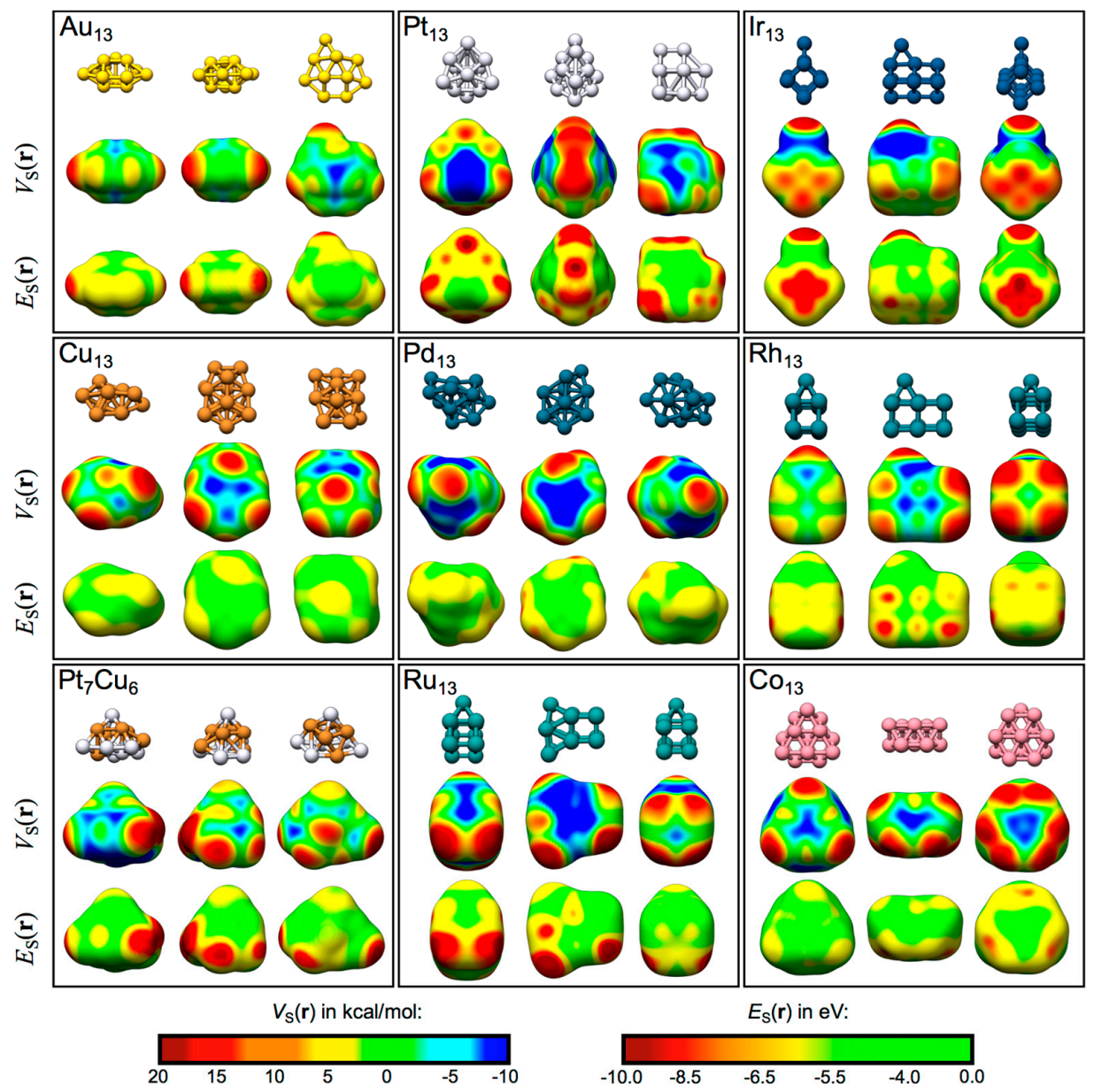

Figure 4. The $\mathrm{TM}_{13}$ nanoparticles shown from different angles with the corresponding $V_{\mathrm{S}}(\mathbf{r})$ and $E_{\mathrm{S}}(\mathbf{r})$ maps obtained at the 0.001 a.u. isodensity surface. The color code is inserted in the bottom right corner. Red and yellow site correspond to Lewis acidic sites, while cyan and blue sites are Lewis basic. Values for the $V_{\mathrm{S}, \max }$ and $E_{\mathrm{S}, \min }$ are given in the supplementary material (Table $\mathrm{S} 4$ ).

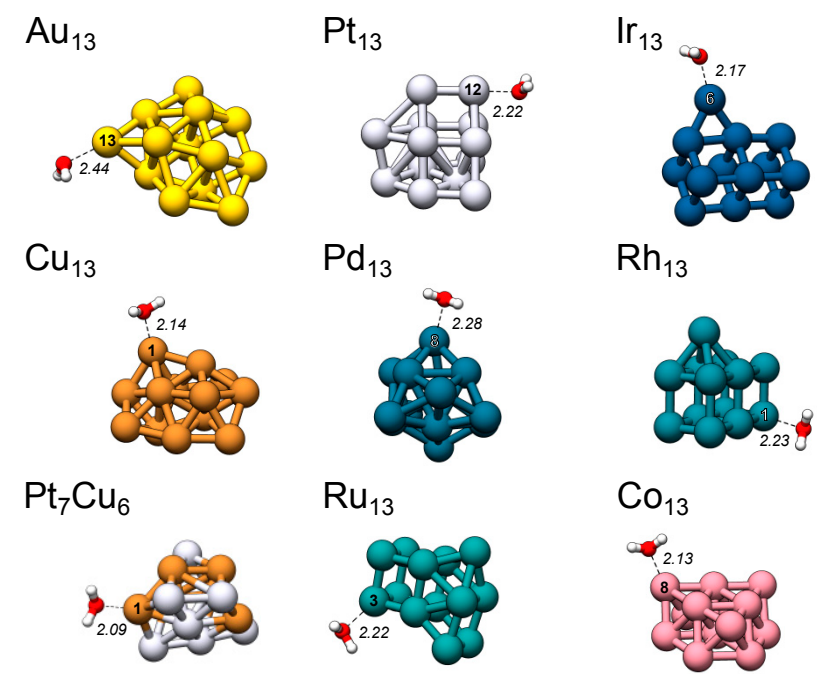

Figure 5. All $\mathrm{TM}_{13}$ nanoparticles with $\mathrm{H}_{2} \mathrm{O}$ adsorbed at the favored position. Interaction distances are given in $\AA$. Refer to the supplementary material for information on the remaining structures (Section S6 and Table S4). 


\subsection{1. $\mathrm{Au}_{13}, \mathrm{Pt}_{13}$ and $\mathrm{Ir}_{13}$}

The low-energy $\mathrm{TM}_{13}$ clusters of $\mathrm{Au}$, $\mathrm{Pt}$ and Ir adopt quite dissimilar structures; $\operatorname{Ir}_{13}$ arrange in an open double cubic $\operatorname{Ir}_{12}$ atomic configuration with a 13th capping Ir ad-atom positioned at a bridge site of one of the elongated sides (see Figure 2) [14]. The $\mathrm{Pt}_{13}$ structure cannot be easily categorized, but comprises atoms with a relatively open arrangement [14]. $\mathrm{Au}_{13}$ has a slightly more compact structure based on a prism $\mathrm{Au}_{6}$ core with capping $\mathrm{Au}$ atoms arranged around it $[19,21-23]$. It should, at this point, be noted that $3 \mathrm{D} \mathrm{Au}_{13}$ nanoclusters are only stable with respect to $2 \mathrm{D}$ clusters if valence electron spin-orbit effects are accounted for [14]. Although such effects are not explicitly included in the present study, we have used the putative global 3D minima structure of $\mathrm{Au}_{13}$ that, presumably, is only metastable at the considered level of theory.

Concerning the electronic structure of $\mathrm{Au}_{13}, \mathrm{Pt}_{13}$ and $\mathrm{Ir}_{13}, \mathrm{NBO}$ analysis [51] suggests that the $6 s$ and $6 p$ occupations vary only slightly over the three nanoclusters. The largest difference instead lies within the $5 d$ orbitals where the $d$-occupation per atom is approximately $d^{10}, d^{9}$ and $d^{8}$ for $\mathrm{Au}_{13}$ (doublet), $\mathrm{Pt}_{13}$ (triplet) and $\operatorname{Ir}_{13}$ (quartet), see Table 1. Similarly to the case of the $\mathrm{TM}_{8}$ example structures in Section 4.1, the $\mathrm{Au}_{13}, \mathrm{Pt}_{13}$ and $\operatorname{Ir}_{13}$ display very different $V_{\mathrm{S}}(\mathbf{r})$ profiles (Figure 4). The principles extracted from the cubic examples are, by and large, manifested also on the $\mathrm{TM}_{13}$ clusters; on $\mathrm{Au}_{13}$, dispersed areas of high electrostatic potential are presented at the tips (on-top sites) of the Au atoms, amounting to one $V_{\mathrm{S} \text {,max }}$ per atom. These $V_{\mathrm{S} \text {, max }}$ are typical $\sigma_{\mathrm{s}}$-holes arising mainly from the partially occupied $6 s$ orbitals. On the other hand, both $\mathrm{Pt}_{13}$ and $\mathrm{Ir}_{13}$, favor the formation of localized $V_{\mathrm{S} \text {, max }}$ that are positioned along the extension of atomic bonds instead of at the tip of an atomic on-top site. Compared to $\mathrm{Au}_{13}$, this gives rise to a larger number of unique $V_{\mathrm{S} \text {,max }}$ on $\mathrm{Pt}_{13}$ and $\operatorname{Ir}_{13}$ with up to three $V_{\mathrm{S} \text {,max }}$ per atomic site. These localized $V_{\mathrm{S} \text {, max }}$ are to a large extent the product of the unsaturated $d$-orbitals of the $\mathrm{Ir}_{13}$ and $\mathrm{Pt}_{13}$ and are typical examples of $\sigma_{d}$-holes. Only two clear cases of $\sigma_{s}$-holes are identified on the $\mathrm{Pt}_{13}$ and $\mathrm{Ir}_{13}$ clusters. One is found above the $\mathrm{Pt}(2)$ site that is surrounded by a large area of low potential. The other $\sigma_{s}$-hole is found at the tip of the ad-atom site of $\operatorname{Ir}_{13}$. For $\mathrm{Pt}_{13}$, areas that superficially appear similar to $\sigma_{\mathrm{s}}$-holes can be identified at the atoms $4,8,10$ and $13 . V_{\mathrm{S} \text {,max }}$ for all of these $\sigma$-holes are, however, located at the extension of TM-TM bonds and arranged according to an $\sigma_{d}$-hole pattern.

Analyzing the profile of the $E_{\mathrm{S}}(\mathbf{r})$ in a similar fashion we find that $E_{\mathrm{S}, \mathrm{min}}$ sites, i.e., sites susceptible to interactions with electron donors, are located at all the observed $V_{\mathrm{S}, \max }$ on $\mathrm{Au}_{13}, \mathrm{Pt}_{13}$, and $\operatorname{Ir}_{13}$ except for the $\mathrm{Au}(12)$ site where no $E_{\mathrm{S} \text {, min }}$ could be identified.

$\mathrm{H}_{2} \mathrm{O}$ molecules positioned at all $V_{\mathrm{S} \text {, max }}$ (and hence $E_{\mathrm{S}, \min }$ ) relaxes O-down to sites close to the initial starting positions, i.e., all unique $\sigma$-holes correspond to a unique adsorption site (see also discussion under Section 4.3 and reference [3]). For $\mathrm{Au}_{13}$, three adsorption positions deviate slightly from the $V_{\mathrm{S} \text {, max }}$ position, namely the atomic sites 7, 10 and 12 , where $\mathrm{H}_{2} \mathrm{O}$ moves towards a side-on position located in the linear extension of an $\mathrm{Au}-\mathrm{Au}$ bond. The $\mathrm{H}_{2} \mathrm{O}$ adsorption data for $\mathrm{Au}_{13}$ were also discussed in reference [3] and found to correlate closely with $\mathrm{CO}$ adsorption. Figure 5 shows the structure of the favored adsorption site for all nanoclusters. Table 2 gives the corresponding adsorption energies, distances and magnitude of the local $V_{\mathrm{S} \text {,max }}$ and $E_{\mathrm{S} \text {,min }}$. We find that there is a clear tendency for $\mathrm{H}_{2} \mathrm{O}$ to prefer the sites with larger magnitudes of $V_{\mathrm{S} \text {,max }}$ (and $E_{\mathrm{S}, \mathrm{min}}$ ). Linear relationships between $V_{\mathrm{S} \text {,max }}$ (and $E_{\mathrm{S}, \min }$ ) and $\mathrm{H}_{2} \mathrm{O}$ interaction energies are discussed further under Section 4.3.

We also investigated $\mathrm{H}_{2} \mathrm{O}$ adsorption towards the areas of low electrostatic potential. $V_{\mathrm{S} \text {,min }}$ sites are generally found at bridge or hollow sites between atoms. For $\mathrm{Au}_{13}$, the most significant $V_{\mathrm{S} \text {, min }}$ is located at the three-fold hollow site between atoms 1,2 and $3\left(\mathrm{~h}_{1-2-3}\right.$, equivalent to the $\mathrm{h}_{5-5-6}$ position) above the central prism motif. $\mathrm{Pt}_{13}$ has its lowest $V_{\mathrm{S}, \min }$ in the four-fold hollow $\mathrm{h}_{1-7-9-12}$ site, and $\operatorname{Ir}_{13}$ at the three-fold hollow $\mathrm{h}_{2-6-7}$ site in proximity to the $\operatorname{Ir}(6)$ ad-atom. For both $\mathrm{Au}_{13}$ and $\mathrm{Pt}_{13}, \mathrm{H}_{2} \mathrm{O}$ preferentially adsorbs $\mathrm{H}$-down $\left(\Delta E_{\text {int }}=-0.23\right.$ and $-0.29 \mathrm{eV}$ for $\mathrm{Au}_{13}$ and $\left.\mathrm{Pt}_{13}\right)$ towards the abovementioned sites, whereas for $\operatorname{Ir}_{13}$, no H-down adsorption mode could be identified but instead $\mathrm{H}_{2} \mathrm{O}$ migrated to an adjacent $V_{\mathrm{S} \text {, max }}$ and adsorbed O-down. A possible explanation for this is the on 
average stronger O-down interaction between $\mathrm{Ir}$ and $\mathrm{H}_{2} \mathrm{O}$ compared to e.g., $\mathrm{Au}$; on $\operatorname{Ir}_{13}$ the flip from $\mathrm{H}$-down to O-down would thus be more beneficial than for $\mathrm{Au}_{13}$.

Table 2. $\mathrm{H}_{2} \mathrm{O}$ adsorption position and the corresponding $V_{\mathrm{S}, \max }(\mathrm{kcal} / \mathrm{mol})$ and $E_{\mathrm{S} \text {, min }}(\mathrm{eV})$ for the $\mathrm{TM}_{13}$ nanocluster. Interaction energies $\left(\Delta E_{\mathrm{int}}\right.$ in $\left.\mathrm{eV}\right)$ and distances $\left(d_{\mathrm{TM}-\mathrm{O}}\right.$ in $\left.\AA\right)$ are also included, as are the $\sigma$-hole character of the $V_{\mathrm{S} \text {, max }}\left(\sigma_{\text {type }}\right)$ and distance from the $V_{\mathrm{S} \text {, max }}$ to the optimized position of the O-atom of $\mathrm{H}_{2} \mathrm{O}$ upon adsorption $\left(d_{\sigma-\mathrm{O}}\right.$ in $\AA$ ) .

\begin{tabular}{|c|c|c|c|c|c|c|c|c|}
\hline & $\mathrm{AS}_{\mathrm{fav}}$ & $V_{\mathrm{S}, \max }$ & $\sigma_{\text {type }}$ & $E_{\mathrm{S}, \min }$ & $\Delta E_{\text {int }}$ & $d_{\mathrm{TM}-\mathrm{O}}$ & $d_{\mathrm{TM}-\sigma}$ & $d_{\sigma-\mathrm{O}}$ \\
\hline $\mathrm{Au}_{13}$ & 13 & 16.80 & $\sigma_{S}$ & -8.88 & -0.37 & 2.44 & 2.20 & 0.48 \\
\hline $\mathrm{Cu}_{13}$ & $1(2)$ & 19.55 & $\sigma_{S}$ & -6.53 & -0.54 & 2.14 & 2.02 & 0.56 \\
\hline $\mathrm{Pt}_{13}$ & 12 & 20.12 & $\sigma_{d}$ & -11.93 & -0.80 & 2.22 & 2.13 & 0.13 \\
\hline $\mathrm{Pt}_{7} \mathrm{Cu}_{6}$ & $1^{1}$ & 35.38 & $\sigma_{S}$ & -10.88 & -0.73 & 2.09 & 1.91 & 0.23 \\
\hline $\mathrm{Pd}_{13}$ & $8(11)^{2}$ & 13.31 & $\sigma_{S}$ & -5.14 & -0.59 & 2.28 & 2.16 & 1.35 \\
\hline $\mathrm{Co}_{13}$ & $8^{3}$ & 21.65 & $\sigma_{S}$ & -5.64 & -0.48 & 2.13 & 2.06 & 0.90 \\
\hline $\mathrm{Rh}_{13}$ & $1(7)$ & 20.43 & $\sigma_{d}$ & -8.74 & -0.81 & 2.23 & 2.13 & 0.27 \\
\hline $\mathrm{Ir}_{13}$ & 6 & 33.75 & $\sigma_{s}$ & -12.86 & -1.00 & 2.17 & 2.18 & 0.33 \\
\hline $\mathrm{Ru}_{13}$ & $3(1)^{4}$ & 29.16 & $\sigma_{S}$ & -12.11 & -0.92 & 2.22 & 2.07 & 0.96 \\
\hline
\end{tabular}

4.2.2. $\mathrm{Rh}_{13}$ and $\mathrm{Ru}_{13}$

The $\mathrm{Rh}_{13}$ and $\mathrm{Ru}_{13}$ clusters' structures arrange in a double cubic $\mathrm{TM}_{12}$ atomic configuration similar to that of $\operatorname{Ir}_{13}$. The 13th TM ad-atom (the capping atom) is, however, positioned at a four-fold hollow site at the extended side for $\mathrm{Ru}_{13}$ and $\mathrm{Rh}_{13}$, instead of at the bridge site position of $\operatorname{Ir}_{13}$ [14]. For $\mathrm{Ru}_{13}$, the cube motif underneath the ad-atom is distorted to form a parallelepiped structure (Figure 4). $\mathrm{Rh}_{13}$ (doublet) belongs to the same group of the periodic table (group 9) as $\operatorname{Ir}_{13}$, but its electronic valence structure is clearly redistributed as compared to $\operatorname{Ir}_{13}$ : NBO analysis suggests a much lower $s$ - and $p$-occupation and an increased d-occupation of $d^{8.3}\left(\operatorname{Ir}_{13}: d^{7.97}\right) . \operatorname{Ru}_{13}$ (tridecatet) shows a similar electronic valence distribution as $\mathrm{Rh}_{13}$, but with a $d^{7.22}$-occupation. An analogous analysis for $\mathrm{Rh}_{13}$ in the decatet spin-state (almost degenerate to the doublet state) is provided in the supplementary material (Section S3, Figure S1, and Tables S3, S5 and S6). This also includes a discussion of the possibly multi-configurational character of $\mathrm{Rh}_{13}$ ( $a n d \mathrm{Ir}_{13}$ ), and the usage of spin-contamination correction schemes.

The electronic structures described above affect the electrostatic potential of $\mathrm{Rh}_{13}$ and $\mathrm{Ru}_{13}$ compounds compared to the closely related $\operatorname{Ir}_{13}$ cluster. From Figure 4 we can conclude that the $V_{\mathrm{S}}(\mathbf{r})$ profiles of the $\mathrm{Rh}_{13}$ and $\mathrm{Ru}_{13}$ clusters have both similarities and differences compared to the $\operatorname{Ir}_{13}$ cluster; for $\mathrm{Rh}_{13}$, the overall appearance of the $V_{\mathrm{S}}(\mathbf{r})$ profile suggest that $\sigma_{d}$-holes are located at the extensions of all $\mathrm{Rh}-\mathrm{Rh}$ bonds, similar to $\operatorname{Ir}_{13}$. However, true $V_{\mathrm{S} \text {, max }}$ could only be identified at the capping atom, as well as on all six sites of the extended cubic side perpendicular to the position of the capping atom with respect to the cubic structure. Could this be an effect of the larger $d$-occupation of $\mathrm{Rh}_{13}$ compared to $\mathrm{Ir}_{13}$, or is it a geometrical effect of the position of the capping atom? While the position of the capping atom could certainly induce some electronic redistribution, the largest effect of its position is probably the split of the $\sigma$-hole of the capping atom into two $\sigma_{d}$-holes $\left(\sigma_{s}\right.$-hole on $\left.\operatorname{Ir}_{13}\right)$. The relatively large $d$-occupation of $\mathrm{Rh}_{13}$ is, on the other hand likely to affect the shape of the $\sigma$-holes. At full $d^{10}$-occupation (e.g., Au), as outlined above, we only expect $\sigma_{s}$-holes. Hence the increased $d$-occupation and reduced $s$-occupation of $\mathrm{Rh}_{13}$ is likely to partly quench the formation of $\sigma_{d}$-holes.

As concerning the $E_{S}(\mathbf{r})$ profile of $\mathrm{Rh}_{13}$ it contains $\sigma_{d}$-holes to a larger degree than $V_{\mathrm{S}}(\mathbf{r})$ with $E_{S, \text { min }}$ located at the extension of all but the 6-3 and 12-9 bonds. There are in fact twice as many $E_{S, \min }$ as $V_{\mathrm{S} \text {,max }}$, suggesting that there remains a driving force (including also charge-transfer-polarization effects) for interactions along the extension of all $\mathrm{Rh}-\mathrm{Rh}$ bonds. 
For $\mathrm{Ru}_{13}$ the positions of the identified $V_{\mathrm{S}, \max }$ are overlapped almost perfectly by $E_{\mathrm{S}, \min }$ sites. However, and similarly to the case of $\mathrm{Rh}_{13}, \mathrm{Ru}_{13}$ displays a larger number of $E_{\mathrm{S} \text {, min }}$ compared to $V_{S, \max }$. A distinct difference compared to $\mathrm{Rh}_{13}$ is, however, that there is a larger amount of $\sigma_{s}$-holes on $\mathrm{Ru}_{13}$. For instance, the $\sigma$-hole located at the capping atom is a $\sigma_{s}$-hole for $\mathrm{Ru}_{13}$, whereas it is a $\sigma_{d}$-hole for $\mathrm{Rh}_{13}$. Characteristic $\sigma_{s}$-holes are also found at atoms 5 and 7 . In addition, the $\sigma_{d}$-holes of the atoms $1,3,9,10,11$ and 12 are clearly distorted from the ideal Ru-Ru bond extension, suggesting a mixed $\sigma_{s / d}$-hole, or alternatively, that the $\sigma_{d}$-holes are to some degree masked by overlapping $\sigma_{s}$-holes. In comparison to $\mathrm{Rh}_{13}, \mathrm{Ru}_{13}$ displays $\sigma$-holes in all directions.

$\mathrm{H}_{2} \mathrm{O}$ adsorption sites (O-down) were found on the $\mathrm{TM}_{13}$ clusters with only moderate deviations from the positions of the $\sigma$-holes for both $\mathrm{Rh}_{13}$ and $\mathrm{Ru}_{13}$ (see further discussion under Section 4.3). Two noteworthy exceptions are adsorption to the 5(7) and 9(10) positions of $\mathrm{Ru}_{13}$ where $\mathrm{H}_{2} \mathrm{O}$ moves from the $\sigma_{d}$ position along the TM-TM bond extensions and instead resides at a typical $\sigma_{s}$ site at an $\mathrm{Ru}-\mathrm{Ru}-\mathrm{O}$ angle significantly deviating from $90^{\circ}$ or $180^{\circ}$. For $\mathrm{Rh}_{13}$, the most favorable position of adsorption corresponds to the site with the highest $V_{\mathrm{S}, \max }$ (atom 1 and 7), whereas for $\mathrm{Ru}_{13}$ the strongest interaction is at position 1 (and 3), which correspond to the second highest $V_{\mathrm{S} \text {, max }}$. The most favored adsorption sites are thus not the capping atoms, which can be explained by a relatively large coordination of these sites, with four neighbors compared to only three for the cubic corner sites ( $c f$. $\operatorname{Ir}_{13}$ where the capping atom only has a coordination number of two and is the favored site of $\mathrm{H}_{2} \mathrm{O}$ adsorption). The global $V_{\mathrm{S} \text {, min }}$ of $\mathrm{Ru}_{13}$ is found at the four-fold hollow $\mathrm{h}_{2-4-9-10}$ site, and for $\mathrm{Rh}_{13}$ at the three-fold hollow $\mathrm{h}_{5-10-13}$ site, which alternatively can be described as a low electrostatic potential ring around the capping atom. Similarly to the case of $\operatorname{Ir}_{13}$, $\mathrm{H}$-down adsorption of $\mathrm{H}_{2} \mathrm{O}$ to $\mathrm{Rh}_{13}$ and $\mathrm{Ru}_{13}$ converges to the O-down adsorption modes.

\subsection{3. $\mathrm{Cu}_{13}$ and $\mathrm{Pt}_{7} \mathrm{Cu}_{6}$}

$\mathrm{Cu}_{13}$ and $\mathrm{Au}_{13}$ have many characteristics in common; both clusters adopt doublet spin-states, approximately fully occupied $d$-orbitals, and are organized in compact atomic configurations. The structure of $\mathrm{Cu}_{13}$ resembles a distorted biplanar hexagonal structure (see also $\mathrm{Co}_{13}$ below) [14]. Analogous to $\mathrm{Au}_{13}$, and in line with the conclusions of ref. [4], the $V_{\mathrm{S}}(\mathbf{r})$ profile of $\mathrm{Cu}_{13}$ displays a delocalized $\sigma_{s}$-hole on top of each atomic site, with areas of low $V_{S}(\mathbf{r})$ located in between the atoms. This profile reflects the dominance of the partially occupied s-orbitals in the $V_{S}(\mathbf{r})$. As for $\mathrm{Au}_{13}$, the positions of the $E_{\mathrm{S} \text {, min }}$ sites of $\mathrm{Cu}_{13}$ coincide well with the $V_{\mathrm{S}, \max } . \mathrm{H}_{2} \mathrm{O}$ adsorbs O-down to the $V_{\mathrm{S} \text {, max }}$ (and $E_{\mathrm{S}, \min }$ ) sites with the optimized position of the interacting $\mathrm{H}_{2} \mathrm{O}$ deviating little from the $V_{\mathrm{S}, \max }$ (and $E_{\mathrm{S}, \min }$ ) positions (see also Section 4.3). H-down adsorption $\left(\Delta E_{\text {int }}=-0.27 \mathrm{eV}\right)$ takes place at the $V_{\mathrm{S} \text {, min }}$ sites, where the most prominent $V_{\mathrm{S} \text {, } \min }$ corresponds to the three-fold hollow $\mathrm{h}_{5-10-12}$ site-this adsorption mode is in line with previous reports of $\mathrm{H}_{2} \mathrm{O}$ interactions with $\mathrm{Cu}$ nanoclusters $[5,58]$.

The low-energy structure of $\mathrm{Pt}_{7} \mathrm{Cu}_{6}$ (triplet) is compact and disordered [15]. The comparison between $\mathrm{Cu}_{13}, \mathrm{Pt}_{13}$ and $\mathrm{Pt}_{7} \mathrm{Cu}_{6}$ gives rise to several questions with regards to the $V_{\mathrm{S}}(\mathbf{r})$. For instance: will $\sigma$-holes occur on both $\mathrm{Pt}$ and $\mathrm{Cu}$ atoms, or will the electrostatic potential be polarized to one atomic type; and if both atom types have associated $\sigma$-holes, will the preference of $\sigma_{d}$-holes for Pt and $\sigma_{s}$-holes for $\mathrm{Cu}$ be mirrored in the alloy nanocluster?

The average electronic valence configuration of $\mathrm{Pt}_{7} \mathrm{Cu}_{6}$ is approximately a mean value of that of the $\mathrm{Cu}_{13}$ and $\mathrm{Pt}_{13}$ clusters. Notably however, the NBO analysis implies that some electron density has been transferred from the $s(p)$-orbitals to the $d$-orbitals (Table 1). In particular, the analysis suggests that the occupation of the $d$-orbitals of $\mathrm{Pt}$ is increased at the expense of, primarily, a reduced $\mathrm{Cu}$ $s$-occupation. This is reflected in the detailed resolution of the $V_{\mathrm{S}}(\mathbf{r})$ of $\mathrm{Pt}_{7} \mathrm{Cu}_{6}$. Whereas all $\mathrm{Cu}$ sites still display one single $\sigma_{s}$-hole on top of each atomic site-expected since the s-occupation still dominates the bonding of the $\mathrm{Cu}$ atoms - the characteristics of the Pt atoms are slightly modified compared to the pure $\mathrm{Pt}$ cluster. For $\mathrm{Pt}$, and despite the average increase of the $d$-occupation, the $\mathrm{Pt}$ atoms do maintain their general preference for formation of $\sigma_{d}$-holes along the extension of $\mathrm{Pt}-\mathrm{Pt}$ bonds. However, when there are no $\mathrm{Pt}$ neighbors, as is the case for e.g., the $\mathrm{Pt}(8)$ atom, $\sigma_{s}$-holes are formed also on the $\mathrm{Pt}$ 
atoms. The $\mathrm{Pt}(8)$ is in addition the $\mathrm{Pt}$ atom that possesses the highest $d$-occupation $\left(d^{9.55}\right)$, and hence electronically shows closest resemblance to $\mathrm{Cu}$. Another notable feature is that only one $\sigma$-hole is identified per $\mathrm{Pt}$ atom, despite the fact that there is a larger number of possible sites along $\mathrm{Pt}-\mathrm{Pt}$ extensions. This is partly attributed to the local bonding symmetry of the $\mathrm{Pt}$ atoms; in e.g., $\mathrm{Pt}_{8}$ or $\mathrm{Pt}_{13}$ the symmetric arrangement of atoms with (close to) linear or perpendicular angels allows for the distinction of different $\sigma_{d}$-holes. In $\mathrm{Pt}_{7} \mathrm{Cu}_{6}$, on the other hand, the disordered cluster structure prevents formation of $V_{\mathrm{S} \text {,max }}$ along the extension of all $\mathrm{Pt}-\mathrm{Pt}$ bonds. The overlap of different contributions to the $V_{\mathrm{S} \text {, max }}$ further leads to the $\sigma_{d}$-holes being slightly distorted from the linear $\mathrm{Pt}-\mathrm{Pt} \ldots \sigma_{d}$ angle. In total, the $\mathrm{Pt}_{7} \mathrm{Cu}_{6}$ cluster has $12 \sigma$-holes, one per atom (regardless if it is $\mathrm{Cu}$ or $\mathrm{Pt}$ ). The exception is $\mathrm{Pt}(7)$, which does not have any $V_{\mathrm{S}, \max }$. Instead, $\mathrm{Pt}(7)$ is surrounded by a large area of low electrostatic potential. One can further conclude that it is both the atomic arrangement and the atom type that determine the magnitude of the local $V_{\mathrm{S}}(\mathbf{r})$; although the $\mathrm{Pt}$ atoms of the $\mathrm{Pt}_{7} \mathrm{Cu}_{6}$ cluster in general are associated with larger $V_{\mathrm{S}, \max }$ than $\mathrm{Cu}$, the overall $V_{\mathrm{S}}(\mathbf{r})$ maximum is located at a $\mathrm{Cu}$ atom.

Regarding the $E_{\mathrm{S}}(\mathbf{r})$, we observe eleven $E_{\mathrm{S} \text {, } \min }$ but only seven coincide with $V_{\mathrm{S} \text {, max }}$. The location of the $E_{\mathrm{S}, \min }$ and $V_{\mathrm{S}, \max }$ overlap for all $\mathrm{Pt}$ atoms (except for the $\mathrm{Pt}(7)$ atom, vide supra), as well as for the $\mathrm{Cu}(1)$ site that display the $E_{\mathrm{S} \text {, min }}$ and $V_{\mathrm{S} \text {, max }}$ with the largest amplitude. For the remaining $\mathrm{Cu}$ atoms, $E_{\mathrm{S} \text {,min }}$ are identified at bridge sites, whereas $V_{\mathrm{S} \text {, max }}$ are located at atomic on-top sites. Upon adsorption of $\mathrm{H}_{2} \mathrm{O}$ to the atomic sites, it converges $\mathrm{O}$-down to the $\sigma$-holes and not to the $E_{\mathrm{S} \text {,min }}$ bridge sites of $\mathrm{Cu}$. For about half of the sites, including both $\mathrm{Cu}$ and $\mathrm{Pt}$ atoms, the $\mathrm{H}_{2} \mathrm{O}$ does, however, show some preference for positions further along the extension of TM-TM bonds-i.e., potential $\sigma_{d}$-hole sites in close proximity to the original $\sigma_{s}$-hole. This includes both $\mathrm{Cu}$ and $\mathrm{Pt}$ sites.

$\mathrm{H}_{2} \mathrm{O}$ adsorbs $\mathrm{H}$-down in proximity to the $\mathrm{Pt}(7)$ site with a $\Delta E_{\text {int }}$ of $-0.30 \mathrm{eV}$.

\subsection{4. $\mathrm{Pd}_{13}$ and $\mathrm{Co}_{13}$}

The low-energy structures of $\mathrm{Co}_{13}$ and $\mathrm{Pd}_{13}$ are closely related [14]; $\mathrm{Co}_{13}$ arranges in a $C_{3}$ hexagonal bilayer structure that is constructed from two overlapping, close-packed hexagonal layers bearing resemblance to the bulk hexagonal close-packing (hcp) of Co. One of the overlapping layers has a triangular shape, while the other is arranged in a honeycomb structure. $\mathrm{Pd}_{13}$ adapts to a distorted hexagonal bilayer structure, similar to that of $\mathrm{Cu}_{13}$. On the average, $\mathrm{Co}_{13}$ has a somewhat decreased $d^{8}$ occupation (NBO: $d^{7.82}$ ), whereas for $\mathrm{Pd}_{13}$ a large redistribution from the $s(p)$ orbitals leads to a notably large $d$-occupation of $d^{9.34}$. Compared to $\mathrm{Pt}_{13}$, where $\mathrm{Pt}$ is placed just below $\mathrm{Pd}$ in the periodic table, the $\mathrm{Pd}_{13}$ cluster has a significantly different $V_{\mathrm{S}}(\mathbf{r})$ profile with one $V_{\mathrm{S} \text {, max }}$ per atom placed on top of the atomic sites. The exception is the 10(13) site that has a split $V_{S, \max }$ resembling two $\sigma_{d}$-holes. Overall $\mathrm{Pd}_{13}$ has an $\sigma_{s}$-hole-dominated $V_{\mathrm{S}}(\mathbf{r})$, whereas the $V_{\mathrm{S}}(\mathbf{r})$ of $\mathrm{Pt}_{13}$ is dominated by $\sigma_{d}$-holes. This can be understood by the increased $d$-occupation of $\mathrm{Pd}_{13}$ compared to $\mathrm{Pt}_{13} . V_{\mathrm{S} \text {, max }}$ and $E_{\mathrm{S} \text {, min }}$ of $\mathrm{Pd}_{13}$ coincide well for the five sites with highest $V_{\mathrm{S} \text {, max }}$, but $E_{\mathrm{S} \text {, min }}$ have a larger tendency to form $\sigma_{d}$-hole equivalents along the extensions of Pd-Pd bonds. $V_{\mathrm{S}, \max }$ and $E_{\mathrm{S}, \min }$ are located at different positions for the 6(12) site, and no $E_{\mathrm{S}, \min }$ could be identified at atom 3 .

$\mathrm{H}_{2} \mathrm{O}$ adsorbs on top and O-down to all $V_{\mathrm{S} \text {, max }}$ of $\mathrm{Pd}_{13}$ with a tendency to move towards the $E_{\mathrm{S} \text {,min }}$ position of atomic site 4(5). The average deviation of the $\mathrm{O}$ positing of $\mathrm{H}_{2} \mathrm{O}$ compared to the $V_{\mathrm{S} \text {, max }}$ is small $\left(d_{\sigma-\mathrm{O}, \text { ave }}=0.67 \AA\right.$, see Section 4.3$)$. The most significant $V_{\mathrm{S}, \min }$ of $\operatorname{Pd}_{13}$ is located at the hollow site of atoms 2(7), 1(9) and 10(13), at which $\mathrm{H}_{2} \mathrm{O}$ adsorbs $\mathrm{H}$-down with an $\Delta E_{\text {int }}$ of $-0.29 \mathrm{eV}$.

For $\mathrm{Co}_{13}$, the $C_{s}$ symmetry results in only four unique atomic on-top adsorption sites: the triangular and honeycomb corner atoms, as well as the triangular edges and the hcp site on top of the honeycomb. The latter is associated with negative electrostatic potential and $\mathrm{H}_{2} \mathrm{O}$ is repelled from this site. Overall, all attempts to identify $\mathrm{H}$-down structures converged to O-down adsorption to the corner and edge sites. The $V_{\mathrm{S} \text {, max }}$ are all of $\sigma_{s}$-type and $\mathrm{H}_{2} \mathrm{O}$ adsorbs $\mathrm{O}$-down to the three unique, positive $\sigma_{s}$-holes with small deviation of the optimized $\mathrm{H}_{2} \mathrm{O}$ position from the location of the $\sigma_{s}$-hole site (see Section 4.3). $E_{\mathrm{S}, \min }$ are identified at the corner and edge $\sigma_{\mathrm{s}}$-hole sites of the triangular side, but for the honeycomb side the $E_{\mathrm{S}, \min }$ are located at the bridge sites. 


\subsection{General Discussion}

From the above discussion, we can conclude on some general features of $\sigma_{s^{-}}$and $\sigma_{d}$-holes. Diffuse and weakly directional $\sigma_{s}$-holes are created when there is an electron deficiency in the s-orbitals. Such deficiencies are present on all the TM nanoclusters, but may in some cases be weak in comparison to the effects of electron deficiencies in the $d$-orbitals. In such cases, the electron polarization within the $d$-orbitals leads to localized and directional $\sigma_{d}$-holes if certain criteria are fulfilled:

- Partially occupied $d$-orbitals

- Favorable electronic configuration (e.g., spin-state with low degree of spd-hybridization)

- Locally symmetric bonding arrangement (e.g., cubic)

The above should be seen in the light of the limited study in the current contribution and future work will be directed towards further understanding of the principles behind the creation of $\sigma_{S^{-}}$and $\sigma_{d}$-holes. We found, however, that in cases where any one of the above criteria is not fulfilled, other types of $\sigma$-holes dominate over the prototypical $\sigma_{d}$-hole. If the $d$-orbitals are fully occupied (e.g., $\mathrm{Au}_{13}$ or $\left.\mathrm{Cu}_{13}\right)$, no $\sigma_{d}$-holes will be present but instead $\sigma_{s}$-holes will appear at the atomic on-top sites located at the corners of the nanoclusters. If the clusters have unsaturated $d$-orbitals but the overall $d$-occupation is large compared to the ideal occupation (e.g., $d^{9}$ in Pt or $d^{8}$ in Ir) —for instance due to a large redistribution of $s$-electrons via $s(p) d$-hybridization - the $\sigma_{d}$-holes will be fully or partially quenched resulting in $\sigma_{s}$-holes or mixed $\sigma_{s / d}$-holes. Examples of this are $\mathrm{Ru}_{13}, \mathrm{Rh}_{13}$, and $\mathrm{Pd}_{13}$. In addition, if the local bonding symmetry is low with TM-TM bond angles deviating significantly from straight or right angles, $\sigma_{d}$-holes may, to a varying degree, be masked by the overlap of the diffuse $\sigma_{s}$-holes or by other $\sigma_{d}$-holes. This effectively yields (pseudo) $\sigma_{s}$-hole or mixed $\sigma_{s / d}$-hole dominated $V_{S}(\mathbf{r})$ profiles, e.g., $\mathrm{Pt}_{7} \mathrm{Cu}_{6}$ or the capping atoms of $\mathrm{Ru}_{13}$ and $\operatorname{Ir}_{13}$.

Overall, the locations of the various $\sigma$-holes coincide well with the sites of O-down $\mathrm{H}_{2} \mathrm{O}$ interactions. As a measure of this, Table 3 includes the average distance $\left(d_{\sigma \text {-O,ave }}\right)$ from the $\sigma$-holes to the optimized position of the $\mathrm{O}$-atom of $\mathrm{H}_{2} \mathrm{O}$ for all of the $\mathrm{TM}_{13}$ nanoclusters. The $d_{\sigma-\mathrm{O} \text {,ave }}$ are generally small and in the order of $0.37-0.91 \AA$. Some few exceptions are outlined in Sections 4.2.2-4.2.4. Additionally, it should be noted that the $d_{\sigma \text {-O,ave }}$ distance includes the difference between the position of the 0.001 isodensity surface relative to the TM atom centers (approximately 2.0-2.3 $\AA$, Table 3) and the binding distance of the $\mathrm{H}_{2} \mathrm{O}$ molecule that adsorbs at slightly larger distances (2.2-2.6 $\AA$ ). In general, there is a trend that the $d_{\sigma \text {-O,ave }}$ deviations for the $\sigma_{d}$-holes are smaller than for the $\sigma_{s}$-holes, in line with the proposed larger directionality of the $\sigma_{d}$-holes compared to the $\sigma_{s}$-holes. The $\sigma_{d}$-holes display, on the average, larger $\Delta E_{\text {int }}(-0.54 \mathrm{eV})$ but reduced $V_{\mathrm{S}, \max }(11.5 \mathrm{kcal} / \mathrm{mol})$ compared to the $\sigma_{s}$-holes (average $\Delta E_{\text {int }}=-0.45 \mathrm{eV}$ and $V_{\mathrm{S}, \max }=13.0 \mathrm{kcal} / \mathrm{mol}$ ). In addition, the maximum $V_{\mathrm{S}, \max }$ and strongest $\Delta E_{\text {int }}$ are clearly larger for $\sigma_{s}$-holes $\left(V_{S, \max }=35.4 \mathrm{kcal} / \mathrm{mol}\right.$ and $\left.\Delta E_{\text {int }}=-1.00 \mathrm{eV}\right)$ compared to $\sigma_{d}$-holes $\left(V_{S, \max }=25.4 \mathrm{kcal} / \mathrm{mol}\right.$ and $\left.\Delta E_{\text {int }}=-0.81 \mathrm{eV}\right)$.

The $E_{\mathrm{S}}(\mathbf{r})$ and $V_{\mathrm{S}}(\mathbf{r})$ profiles show a strong mutual correlation where $E_{\mathrm{S}, \min }$ and $V_{\mathrm{S}, \max }$ sites generally overlap well, with some notable exceptions (see the discussion in Sections 4.2.2-4.2.4). The mutual correlation is not surprising bearing in mind that the $E_{S}(\mathbf{r})$ property includes a contribution from $V_{\mathrm{S}}(\mathbf{r})$ (cf. Equation (4)). From a computational point of view this is an attractive feature of $E_{S}(\mathbf{r})$, because the computation of $V_{\mathrm{S}}(\mathbf{r})$ is significantly more time-consuming than that of $E_{\mathrm{S}}(\mathbf{r})$. The two quantities do, however, to a certain extent yield different and complementary information; $E_{S}(\mathbf{r})$ provides, besides information on electrostatics, a measure of the charge-transfer and polarization effects. Table 3 includes $R^{2}$ (coefficient of determination) values for the correlation between the site resolved $\mathrm{H}_{2} \mathrm{O}$ interaction energies and the local $E_{S, \min }$ and $V_{S, \max }$. As can be seen, there are clear correlations for both $E_{\mathrm{S} \text {, min }}$ and $V_{\mathrm{S}, \max }$, especially for the $\mathrm{Au}, \mathrm{Cu}$ and $\mathrm{Pt}$ compounds. $\mathrm{Pd}_{13}$ shows weak correlations, while for $\mathrm{Ru}_{13}, \mathrm{Ir}_{13}$ and $\mathrm{Rh}_{13}$ the correlations are poor. Some insight into why certain trends are strong and others weak can be gained from the $\operatorname{Ir}_{13}$ case. Here there are 17 unique adsorption sites. By including only the eight sites with the strongest $V_{\mathrm{S}, \max }$, a correlation of $R^{2}=0.90$ can be found 
between $V_{\mathrm{S}, \max }$ and $\Delta E_{\mathrm{int}}$. For the sites with weaker $V_{\mathrm{S} \text {,max }}$ one can thus argue that factors other than electrostatics become dominant for the interaction.

Table 3. Averaged data for the $\mathrm{TM}_{13}$ series: average $\mathrm{O}$-down interaction energies $\left(\Delta E_{\text {int }}\right.$ in $\left.\mathrm{eV}\right)$ and adsorption distances $\left(d_{\mathrm{TM}-\mathrm{O} \text {,ave }}\right.$ in $\AA$ ), as well as average distances from the nearby TM atom to the closest $\sigma$-hole upon $\mathrm{H}_{2} \mathrm{O}$ interaction $\left(d_{\mathrm{TM}-\sigma \text {,ave }}\right)$, and the distance between the $\sigma$-hole and the $\mathrm{O}$ atom of the adsorbed $\mathrm{H}_{2} \mathrm{O}\left(d_{\sigma-\mathrm{O} \text {,ave }}\right)$. Included are also the coefficient of determination $\left(R^{2}\right)$ for the correlation between the $\mathrm{H}_{2} \mathrm{O}$ interaction energies and the local $V_{\mathrm{S} \text {, max }}\left(R^{2} \mathrm{~V}\right)$ or $E_{\mathrm{S}, \min }\left(R_{\mathrm{E}}^{2}\right)$.

\begin{tabular}{|c|c|c|c|c|c|c|}
\hline & $\Delta E_{\text {int,ave }}$ & $d_{\text {TM-O,ave }}$ & $d_{\text {TM- } \sigma, \text { ave }}$ & $d_{\sigma-\mathrm{O}, \mathrm{ave}}$ & $R^{2} \mathrm{~V}$ & $R^{2} \mathrm{E}$ \\
\hline $\mathrm{Au}_{13}$ & -0.29 & 2.57 & 2.21 & 0.83 & 0.84 & 0.81 \\
\hline $\mathrm{Cu}_{13}$ & -0.47 & 2.19 & 2.06 & 0.43 & 0.85 & 0.95 \\
\hline $\mathrm{Pt}_{13}$ & -0.47 & 2.38 & 2.20 & 0.46 & $0.67^{1}$ & $0.82^{1}$ \\
\hline $\mathrm{Pt}_{7} \mathrm{Cu}_{6}$ & $-0.47^{2}$ & $2.30^{2}$ & 2.09 & $0.57^{2}$ & $0.92^{2}$ & $0.65^{2}$ \\
\hline $\mathrm{Pd}_{13}$ & -0.45 & 2.34 & 2.15 & 0.82 & 0.58 & 0.25 \\
\hline $\mathrm{Co}_{13}$ & -0.470 & 2.15 & 2.10 & 0.61 & n.a. ${ }^{3}$ & n.a. ${ }^{3}$ \\
\hline $\mathrm{Rh}_{13}$ & -0.64 & 2.29 & 2.15 & 0.37 & 0.19 & 0.18 \\
\hline $\operatorname{Ir}_{13}$ & -0.59 & 2.41 & 2.28 & 0.45 & $0.28(0.90)^{4}$ & $0.09(0.75)^{4}$ \\
\hline $\mathrm{Ru}_{13}$ & -0.64 & 2.25 & 2.17 & 0.91 & 0.03 & 0.10 \\
\hline
\end{tabular}

${ }^{1}$ Including only the sites with identified $V_{\mathrm{S}, \max } \cdot{ }^{2}$ Values resolved for the $\mathrm{Cu}(\mathrm{Pt})$ atoms are, in the order of the table columns: $-0.46(-0.45), 2.22(2.39), 2.00(2.17), 0.62(0.52), 0.99(0.85)$, and $0.98(0.81)$. ${ }^{3}$ Not applicable since there are only three unique adsorption sites. ${ }^{4}$ Including only the eight strongest interaction sites.

The difficulties for $V_{\mathrm{S}, \max }$ and $E_{\mathrm{S}, \min }$ for ranking reactivity are most pronounced for the particles that have stronger interactions as well as for the particles that have partially occupied $d$-states (with the possible exception of $\mathrm{Pt})$. Since $E_{S}(\mathbf{r})$ and $V_{S}(\mathbf{r})$ are ground-state properties, it is reasonable that a strong, partly covalent interaction (e.g., $\mathrm{Ru}_{13}$ or $\mathrm{Rh}_{13}$ ) that is associated with a large redistribution of the electronic configuration is more difficult to describe compared to a weak, non-covalent interaction (e.g., $\mathrm{Cu}_{13}$ ). The DFT methods are, in addition, known to exhibit difficulties in describing the multi-configurational character of certain TM elements, the exceptions being e.g., $\mathrm{Au}, \mathrm{Ag}$ and $\mathrm{Cu}$, whereas, as discussed further in the supplementary material (Sections S1 and S3), large spin contaminations are found for $\operatorname{Ir}_{13}$ and, especially, $\mathrm{Rh}_{13}$, indicating possible multi-configurational states. It can, moreover, be noted that the $d$-band model has also been reported to fail to reproduce adsorption trends for e.g., the $\mathrm{Rh}_{13}$, $\mathrm{Ir}_{13}$ and $\mathrm{Pt}_{13}$ nanoclusters [16].

As discussed above, both $E_{\mathrm{S}, \min }$ and $V_{\mathrm{S}, \max }$ can successfully be used to rank the adsorption trends of $\mathrm{Au}_{13}, \mathrm{Pt}_{13}, \mathrm{Cu}_{13}$ and $\mathrm{Pt}_{7} \mathrm{Cu}_{6}$. Figure 6 shows as an example the $\Delta E_{\text {int }}$ of $\mathrm{H}_{2} \mathrm{O}$ versus $E_{\mathrm{S}, \min }$ and $V_{\mathrm{S}, \max }$ resolved for all the combined $\mathrm{Cu}$ and $\mathrm{Pt}$ atoms of the $\mathrm{Pt}_{13}, \mathrm{Cu}_{13}$ and $\mathrm{Pt}_{7} \mathrm{Cu}_{6}$ compounds. It illustrates that the adsorption characteristics can be ranked also when including sites from multiple clusters. The trends are strong for $\mathrm{Cu}$ and weaker, but still clear, for Pt.
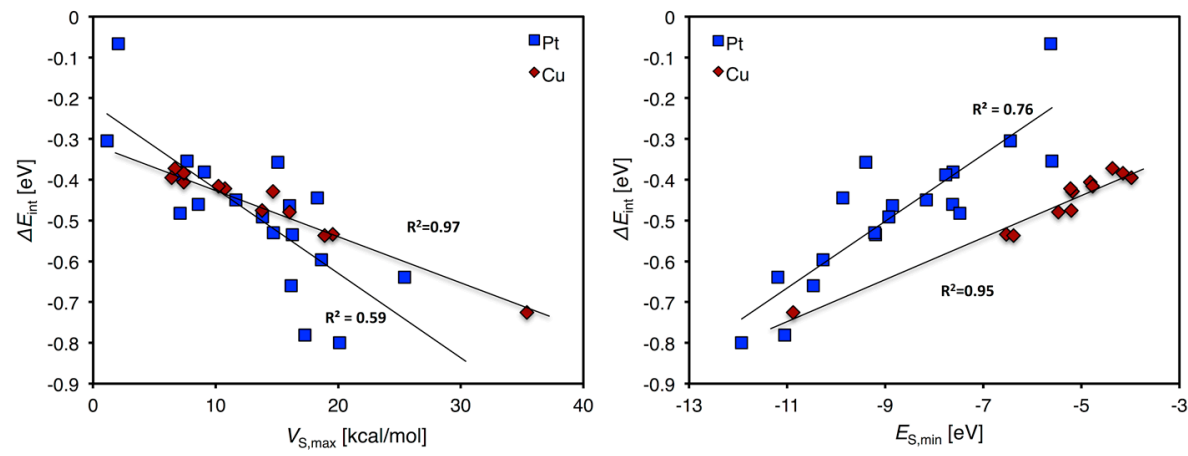

Figure 6. Shows the total correlation for $\mathrm{Pt}$ (blue squares) and $\mathrm{Cu}$ (red rhombs) atoms for the site resolved $\mathrm{H}_{2} \mathrm{O}$ interaction energy of the $\mathrm{Pt}_{13}, \mathrm{Pt}_{7} \mathrm{Cu}_{6}$ and $\mathrm{Cu}_{13}$ nanoclusters combined (e.g., are all $\mathrm{Pt}$ atoms of all three compounds in the Pt series) versus the local $V_{\mathrm{S}, \max }(\mathbf{l e f t})$ and $E_{\mathrm{S}, \min }$ (right). 
We lastly note that the localized $V_{\mathrm{S}, \max }\left(\sigma_{d}\right.$-holes) of the $\mathrm{TM}_{13}$ nanoclusters bear some resemblance to the concept of the $\pi$-holes [59], i.e., $V_{\mathrm{S}, \max }$ positioned perpendicular to the molecular (here particle) framework. In addition, and in analogy to the $\sigma$ - and $\pi$-hole concept, one could also claim that the reported localized $V_{\mathrm{S} \text {, max }}$ for some of the nanoclusters are in-fact $\delta$-holes since these appear primarily as a consequence of electron deficiencies in the $d$-states of the clusters. However, based on the positions of the $V_{\mathrm{S} \text {, } \max }$ along the lateral extensions of the metal-metal bonds, i.e., in the direction of the nanoclusters' $\sigma$-bonding system?either along the extensions of TM-TM $\sigma_{\mathrm{d}}$-bonds or at the focal points (often at atomic on-top sites) of the joint s-orbital states of the cluster?we conclude that the $V_{\mathrm{S} \text {, max }}$ identified on the TM nanoclusters are best described as $\sigma$-holes and that these can be divided into $\sigma_{s^{-}}$and $\sigma_{d}$-holes.

\section{Conclusions}

We have herein discussed different types of maxima in the surface electrostatic potential, $V_{\mathrm{S}, \max }$ also known as $\sigma$-holes, and their influence on the local Lewis acidity of TM nanoclusters. A new categorization is introduced where $\sigma$-holes are denoted $\sigma_{s}, \sigma_{p}$ or $\sigma_{d}$ depending on whether their origin can primarily be traced to the $s-, p$ - or $d$-occupation. It is demonstrated that highly localized and directional $\sigma_{d}$-holes appear at the extension of TM-TM bonds when there is partially occupied $d$-orbitals, a relatively weak $s(p) d$-hybridization, and locally beneficial bonding symmetry. Under other circumstances, diffuse and weakly directional $\sigma_{s}$-holes that correspond to the half-filled s-orbitals-or similarly diffuse and mixed $\sigma_{s / d}$-holes (from the summarized contribution of the valence orbitals formed by the hybridization of $s-,[p$-] and $d$-orbitals)—dominate the surface electrostatic potential profile. In addition, the localized $\sigma_{d}$-holes can be fully or partly masked by the overlap of the diffuse $\sigma_{s}$-holes if such are present.

By studying a series of different $\mathrm{TM}_{13}$ nanoclusters, we have found, for example, that low-energy clusters of $\mathrm{Ir}_{13}, \mathrm{Pt}_{13}, \mathrm{Rh}_{13}, \mathrm{Ru}_{13}$ and $\mathrm{Pt}_{7} \mathrm{Cu}_{6}$ exhibit $\sigma_{d}$-holes. In contrast, only $\sigma_{s}$-holes and $\sigma_{s} / d$-holes are found on the $\mathrm{Au}_{13}, \mathrm{Cu}_{13}, \mathrm{Pd}_{13}$, and $\mathrm{Co}_{13}$ nanoclusters. No $\sigma_{p}$-holes were identified on the $\mathrm{TM}_{13}$ structures, but we argue that such holes are found on e.g., singly coordinated halogen atoms.

Regardless of the character of the $V_{\mathrm{S}, \max }$ (be it $\sigma_{s}$ or $\sigma_{d}$ ), the interactions of the $\mathrm{TM}_{13}$ nanoclusters with water are found to be directed by the position of the $V_{\mathrm{S} \text {, max }}$ with $\mathrm{H}_{2} \mathrm{O}$ adsorbing O-down at the site of the $V_{\mathrm{S}, \max }$. Similarly, we found that areas of low surface electrostatic potential $\left(V_{\mathrm{S}, \mathrm{min}}\right)$ on all but the $\mathrm{Ir}_{13}, \mathrm{Rh}_{13}$ and $\mathrm{Ru}_{13}$ nanoclusters gave rise to a $\mathrm{H}$-down adsorption mode of $\mathrm{H}_{2} \mathrm{O}$. We furthermore note that the magnitude of the $V_{\mathrm{S} \text {, max }}$ can be used to rank the interaction energies of $\mathrm{H}_{2} \mathrm{O}$ O-down adsorption with particularly strong correlations for the $d^{10} s^{1} \mathrm{TM}$ elements as well as for Pt. Similarly, the local electron attachment energy quantity $\left[E_{S}(\mathbf{r})\right]$ can be used to identify adsorption sites, minima in $E_{S}(\mathbf{r})$ coincide well with the identified $V_{S, \max }$ and $\mathrm{H}_{2} \mathrm{O}$ adsorption positions with some few exceptions. $E_{\mathrm{S}}(\mathbf{r})$ can also be used to rank the $\mathrm{H}_{2} \mathrm{O}$ interaction energies for especially the $d^{10} s^{1} \mathrm{TM}$ elements, as well as Pt nanoclusters.

Based on the findings of the present study, we predict that both $V_{\mathrm{S}}(\mathbf{r})$ and $E_{\mathrm{S}}(\mathbf{r})$ quantities will find general use in the study and rationalization of the interaction behavior of TM nanomaterials. We envisage applications in e.g., heterogeneous catalysis, medical therapy, drug delivery systems, nanotoxicity, sorption studies, dissolution and nucleation, as well as in nanoparticle transportation. Future studies should evaluate the applicability of $V_{S}(\mathbf{r})$ and $E_{S}(\mathbf{r})$ to e.g., larger TM and oxide particles, and to surfaces. Furthermore, they should include a thorough benchmark of the applicability of different DFT methods and basis sets.

Supplementary Materials: The following are available online at www.mdpi.com/2073-4352/7/7/222/s1, Figure S1: $V_{\mathrm{S}}(\mathrm{r}), E_{\mathrm{S}}(\mathrm{r})$ and the favored $\mathrm{H}_{2} \mathrm{O}$ adsorption structure for $\mathrm{Rh}_{13}$ at the decatet spin-state; Table S1: spin multiplicity and $<\mathrm{S}^{2}>$ expectation values for the $\mathrm{Pt}_{4}$ and $\mathrm{TM}_{8}$ nanoclusters; Table S2: spin multiplicity and $<\mathrm{S}^{2}>$ expectation values for the $\mathrm{TM}_{13}$ nanoclusters; Table S3: spin projection corrected and non-corrected $\mathrm{H}_{2} \mathrm{O}$ interaction energies for $\mathrm{Ir}_{13}$ and $\mathrm{Rh}_{13}$; Table S4: site-resolved $\mathrm{H}_{2} \mathrm{O}$ adsorption data, $V_{\mathrm{S} \text {,max }}$, and $E_{\mathrm{S} \text {, min }}$ for all $\mathrm{TM}_{13}$ nanoclusters; Table S5: the number of $V_{\mathrm{S}, \max }$, and $E_{\mathrm{S}, \min }$ as well as the $s_{-}, d$ - and $p$-occupation for $\mathrm{Rh}_{13}$ at the decatet spin-state; Table S6: site-resolved $\mathrm{H}_{2} \mathrm{O}$ adsorption data, $V_{\mathrm{S} \text {, max }}$, and $E_{\mathrm{S} \text {, min }}$ for $\mathrm{Rh}_{13}$ at the decatet spin-state; additional computational data for Figures 1 and 3; optimized coordinates; supplementary references [60-72]. 
Acknowledgments: Funding from the Swedish Nuclear Fuel and Waste Management Company (SKB) and the KTH CHE Excellence award (JHS) is gratefully acknowledged. The calculations were performed at resources provided by the Swedish National Infrastructure for Computing (SNIC) at the National Supercomputer Centre in Linköping University NSC as well as at the PDC Centre for High Performance Computing (PDC-HPC). A special thanks is directed to Dr. Juarez L. F. Da Silva and Dr. Anderson S. Chaves for providing coordinates of their optimized $\mathrm{TM}_{13}$ nanoclusters.

Author Contributions: Joakim H. Stenlid and Tore Brinck conceived and designed the computational study; Joakim H. Stenlid performed the calculations; Joakim H. Stenlid, Adam Johannes Johansson and Tore Brinck analyzed the data; Joakim H. Stenlid, Adam Johannes Johansson and Tore Brinck wrote the paper.

Conflicts of Interest: The authors declare no conflict of interest.

\section{References}

1. Clark, T.; Hennemann, M.; Murray, J.; Politzer, P. Halogen bonding: The $\sigma$-hole. J. Mol. Model. 2007, 13, 291-296. [CrossRef] [PubMed]

2. Murray, J.S.; Politzer, P. The electrostatic potential: An overview. Wiley. Interdiscip. Rev. Comput. Mol. Sci. 2011, 1, 153-163. [CrossRef]

3. Stenlid, J.H.; Brinck, T. Unpublished work, 2017.

4. Stenlid, J.H.; Johansson, A.J.; Brinck, T. Unpublished work, 2017.

5. Stenlid, J.H.; Johansson, A.J.; Brinck, T. Searching for the thermodynamic limit-A DFT study of the step-wise water oxidation of the bipyramidal $\mathrm{Cu}_{7}$ cluster. Phys. Chem. Chem. Phys. 2014, 16, 2452-2464. [CrossRef] [PubMed]

6. Farmanzadeh, D.; Abdollahi, T. Investigation on the chemical active sites of copper nanoclusters as nanocatalyst for the adsorption of acetylene: Calibration of DFT method and basis set. Theor. Chem. Acc. 2016, 135, 1-14. [CrossRef]

7. Farmanzadeh, D.; Abdollahi, T. A model for the ethylene and acetylene adsorption on the surface of $\mathrm{Cu}_{\mathrm{n}}(\mathrm{n}=10-15)$ nanoclusters: A theoretical study. Appl. Surf. Sci. 2016, 385, 241-248. [CrossRef]

8. Shields, Z.P.; Murray, J.S.; Politzer, P. Directional tendencies of halogen and hydrogen bonds. Int. J. Quantum Chem. 2010, 110, 2823-2832. [CrossRef]

9. Politzer, P.; Lane, P.; Concha, M.C.; Ma, Y.; Murray, J.S. An overview of halogen bonding. J. Mol. Model. 2007, 13, 305-311. [CrossRef] [PubMed]

10. Brinck, T.; Murray, J.S.; Politzer, P. Surface electrostatic potentials of halogenated methanes as indicators of directional intermolecular interactions. Int. J. Quantum Chem. 1992, 44, 57-64. [CrossRef]

11. Adamo, C.; Barone, V. Toward reliable density functional methods without adjustable parameters: The PBE0 model. J. Chem. Phys. 1999, 110, 6158-6170. [CrossRef]

12. Weigend, F.; Ahlrichs, R. Balanced basis sets of split valence, triple zeta valence and quadruple zeta valence quality for H to Rn: Design and assessment of accuracy. Phys. Chem. Chem. Phys. 2005, 7, 3297. [CrossRef] [PubMed]

13. TURBOMOLE V6.4 2012, a Development of University of Karlsruhe and Forschungszentrum Karlsruhe GmbH, 1989-2007, TURBOMOLE GmbH, Since 2007. Available online: http://www.turbomole.com (accessed on 28 March 2017).

14. Piotrowski, M.J.; Piquini, P.; Da Silva, J.L.F. Density functional theory investigation of 3d, 4d, and 5d 13-atom metal clusters. Phys. Rev. B 2010, 81, 155446. [CrossRef]

15. Chaves, A.S.; Piotrowski, M.J.; Guedes-Sobrinho, D.; Da Silva, J.L.F. Theoretical Investigation of the Adsorption Properties of $\mathrm{CO}, \mathrm{NO}$, and $\mathrm{OH}$ on Monometallic and Bimetallic 13-Atom Clusters: The example of $\mathrm{Cu}_{13}, \mathrm{Pt}_{7} \mathrm{Cu}_{6}$, and $\mathrm{Pt}_{13}$. J. Phys. Chem. A 2015, 119, 11565-11573. [CrossRef] [PubMed]

16. Piotrowski, M.J.; Piquini, P.; Zeng, Z.; Da Silva, J.L.F. Adsorption of $\mathrm{NO}$ on the $\mathrm{Rh}_{13}, \mathrm{Pd}_{13}, \mathrm{Ir}_{13}$, and $\mathrm{Pt}_{13}$ clusters: A density functional theory investigation. J. Phys. Chem. C 2012, 116, 20540-20549. [CrossRef]

17. Li, H.; Zhao, X.; Wei, D.; Li, L.; Li, S. Unexpected odd-even oscillation in the enhanced chemical activities of the $\mathrm{Ru}_{\mathrm{n}}(\mathrm{n}=2-14)$ Nanoclusters for $\mathrm{H}_{2} \mathrm{O}$ adsorption and splitting. J. Phys. Chem. C 2017, 121, 7188-7198. [CrossRef]

18. Piotrowski, M.J.; Piquini, P.; Cândido, L.; Da Silva, J.L.F. The role of electron localization in the atomic structure of transition-metal 13-atom clusters: the example of $\mathrm{Co}_{13}, \mathrm{Rh}_{13}$, and $\mathrm{Hf}_{13}$. Phys. Chem. Chem. Phys. 2011, 13, 17242-17248. [CrossRef] [PubMed] 
19. Beret, E.C.; Ghiringhelli, L.M.; Scheffler, M. Free gold clusters: Beyond the static, monostructure description. Faraday Discuss. 2011, 152, 153-167. [CrossRef] [PubMed]

20. Oezaslan, M.; Heggen, M.; Strasser, P. Size-dependent morphology of dealloyed bimetallic catalysts: Linking the nano to the macro scale. J. Am. Chem. Soc. 2012, 134, 514-524. [CrossRef] [PubMed]

21. Gruber, M.; Heimel, G.; Romaner, L.; Brédas, J.-L.; Zojer, E. First-principles study of the geometric and electronic structure of $\mathrm{Au}_{13}$ clusters: Importance of the prism motif. Phys. Rev. B 2008, 77, 165411. [CrossRef]

22. Sun, J.; Xie, X.; Cao, B.; Duan, H. A density-functional theory study of $\mathrm{Au}_{13}, \mathrm{Pt} 13, \mathrm{Au}_{12} \mathrm{Pt}_{\text {and }} \mathrm{Pt}_{12} \mathrm{Au}_{\text {clusters. }}$ Comput. Theor. Chem. 2017, 1107, 127-135. [CrossRef]

23. Amft, M.; Johansson, B.; Skorodumova, N.V. Influence of the cluster dimensionality on the binding behavior of $\mathrm{CO}$ and $\mathrm{O}_{2}$ on $\mathrm{Au}_{13}$. J. Chem. Phys. 2012, 136, 24312. [CrossRef] [PubMed]

24. Ferrando, R.; Jellinek, J.; Johnston, R.L. Nanoalloys: From theory to applications of alloy clusters and nanoparticles. Chem. Rev. 2008, 108, 845-910. [CrossRef] [PubMed]

25. Kim, J.; Dick, J.E.; Bard, A.J. Advanced electrochemistry of individual metal clusters electrodeposited atom by atom to nanometer by nanometer. Acc. Chem. Res. 2016, 49, 2587-2595. [CrossRef] [PubMed]

26. Luo, Z.; Castleman, A.W.; Khanna, S.N. Reactivity of metal clusters. Chem. Rev. 2016, 116, 14456-14492. [CrossRef] [PubMed]

27. Haruta, M.; Daté, M. Advances in the catalysis of Au nanoparticles. Appl. Catal. A 2001, 222, $427-437$. [CrossRef]

28. Zhou, N.; López-Puente, V.; Wang, Q.; Polavarapu, L.; Pastoriza-Santos, I.; Xu, Q.-H. Plasmon-enhanced light harvesting: Applications in enhanced photocatalysis, photodynamic therapy and photovoltaics. RCS Adv. 2015, 5, 29076-29097. [CrossRef]

29. Di Pietro, P.; Strano, G.; Zuccarello, L.; Satriano, C. Gold and silver nanoparticles for applications in theranostics. Curr. Top. Med. Chem. 2016, 16, 3069-3102. [CrossRef]

30. Kopp, M.; Kollenda, S.; Epple, M. Nanoparticle-protein interactions: Therapeutic approaches and supramolecular chemistry. Acc. Chem. Res. 2017, 50, 1383-1390. [CrossRef] [PubMed]

31. Kwatra, D.; Venugopal, A.; Anant, S. Nanoparticles in radiation therapy: A summary of various approaches to enhance radiosensitization in cancer. Transl. Cancer Res. 2013, 2, 330-342.

32. Liu, P.; Qin, R.; Fu, G.; Zheng, N. Surface coordination chemistry of metal nanomaterials. J. Am. Chem. Soc. 2017, 139, 2122-2131. [CrossRef] [PubMed]

33. Brinck, T.; Carlqvist, P.; Stenlid, J.H. The local electron attraction energy and its use for predicting nucleophilic reactions and halogen bonding. J. Phys. Chem. A 2016, 120, 10023-10032. [CrossRef] [PubMed]

34. Stenlid, J.H.; Brinck, T. Nucleophilic aromatic substitution reactions described by the local electron attachment energy. J. Org. Chem. 2017, 82, 3072-3083. [CrossRef] [PubMed]

35. Stewart, R.F. On the mapping of electrostatic properties from Bragg diffraction data. Chem. Phys. Lett. 1979, 65, 335-342. [CrossRef]

36. Politzer, P.; Truhlar, D.G. Chemical Applications of Atomic and Molecular Electrostatic Potentials; Plenum Press: Berlin, Germany, 1981.

37. Janak, J.F. Proof that $\partial \mathrm{E} / \partial \mathrm{n}_{\mathrm{i}}=\varepsilon_{\mathrm{i}}$ in density-functional theory. Phys. Rev. B 1978, 18, 7165-7168. [CrossRef]

38. Ehresmann, B.; Martin, B.; Horn, A.H.C.; Clark, T. Local molecular properties and their use in predicting reactivity. J. Mol. Model. 2003, 9, 342-347. [CrossRef] [PubMed]

39. Clark, T. The local electron affinity for non-minimal basis sets. J. Mol. Model. 2010, 16, 1231-1238. [CrossRef] [PubMed]

40. Politzer, P.; Murray, J.S.; Bulat, F.A. Average local ionization energy: A review. J. Mol. Model. 2010, 16, 1731-1742. [CrossRef] [PubMed]

41. Sjoberg, P.; Murray, J.S.; Brinck, T.; Politzer, P. Average local ionization energies on the molecular surfaces of aromatic systems as guides to chemical reactivity. Can. J. Chem. 1990, 68, 1440-1443. [CrossRef]

42. Bulat, F.A.; Levy, M.; Politzer, P. Average local ionization energies in the Hartree-Fock and Kohn-Sham theories. J. Phys. Chem. A 2009, 113, 1384-1389. [CrossRef] [PubMed]

43. Grimme, S.; Antony, J.; Ehrlich, S.; Krieg, H. A consistent and accurate ab initio parametrization of density functional dispersion correction (DFT-D) for the 94 elements H-Pu. J. Chem. Phys. 2010, 132, 154104. [CrossRef] [PubMed]

44. Grimme, S.; Ehrlich, S.; Goerigk, L. Effect of the damping function in dispersion corrected density functional theory. J. Comput. Chem. 2011, 32, 1456-1465. [CrossRef] [PubMed] 
45. Pettersen, E.F.; Goddard, T.D.; Huang, C.C.; Couch, G.S.; Greenblatt, D.M.; Meng, E.C.; Ferrin, T.E. UCSF Chimera-A visualization system for exploratory research and analysis. J. Comput. Chem. 2004, 25, 1605-1612. [CrossRef] [PubMed]

46. Frisch, M.J.; Trucks, G.W.; Schlegel, H.B.; Scuseria, G.E.; Robb, M.A.; Cheeseman, J.R.; Scalmani, G.; Barone, V.; Mennucci, B.; Petersson, G.A.; et al. Gaussian 09, Revision D.01. Gaussian, Inc.: Wallingford, CT, USA, 2009.

47. Neese, F. The ORCA program system. WIREs Comput. Mol. Sci. 2012, 2, 73-78. [CrossRef]

48. Neese, F.; Wennmohs, F.; Hansen, A.; Becker, U. Efficient, approximate and parallel Hartree-Fock and hybrid DFT calculations. A “chain-of-spheres" algorithm for the Hartree-Fock exchange. Chem. Phys. 2009, 356, 98-109. [CrossRef]

49. Seeger, R.; Pople, J.A. Self-consistent molecular orbital methods. XVIII. Constraints and stability in Hartree-Fock theory. J. Chem. Phys. 1977, 66, 3045-3050. [CrossRef]

50. Bauernschmitt, R.; Ahlrichs, R. Stability analysis for solutions of the closed shell Kohn-Sham equation. J. Chem. Phys. 1996, 104, 9047-9052. [CrossRef]

51. Glendening, E.D.; Reed, A.E.; Carpenter, J.E.; Weinhold, F. The NBO 3.1 Program Manual; Theoretical Chemistry Institute and Department of Chemistry, University of Wisconsin: Madison, WI, USA, 1990.

52. Kozuch, S. Should "anion $-\pi$ interactions" be called "anion- $\sigma$ interactions"? A revision of the origin of some hole-bonds and their nomenclature. Phys. Chem. Chem. Phys. 2016, 18, 30366-30369. [CrossRef] [PubMed]

53. Böyükata, M.; Belchior, J.C. Structural and energetic analysis of copper clusters: MD study of $\mathrm{Cu}_{n}(\mathrm{n}=2-45)$. J. Braz. Chem. Soc. 2008, 19, 884-893. [CrossRef]

54. Hu, Z.; Boyd, R.J. Structure sensitivity and cluster size convergence for formate adsorption on copper surfaces: A DFT cluster model study. J. Chem. Phys. 2000, 112, 9562-9568. [CrossRef]

55. Itoh, M.; Kumar, V.; Adschiri, T.; Kawazoe, Y. Comprehensive study of sodium, copper, and silver clusters over a wide range of sizes $2 \leq \mathrm{N} \leq 75$. J. Chem. Phys. 2009, 131, 174510. [CrossRef] [PubMed]

56. Wang, G.-C.; Jiang, L.; Pang, X.-Y.; Nakamura, J. Cluster and periodic DFT calculations: The adsorption of atomic nitrogen on $\mathrm{M}(111)(\mathrm{M}=\mathrm{Cu}, \mathrm{Ag}$, Au) surfaces. J. Phys. Chem. B 2005, 109, 17943-17950. [CrossRef] [PubMed]

57. Oviedo, J.; Palmer, R.E. Amorphous structures of $\mathrm{Cu}, \mathrm{Ag}$, and $\mathrm{Au}$ nanoclusters from first principles calculations. J. Chem. Phys. 2002, 117, 9548-9551. [CrossRef]

58. Stenlid, J.H.; Johansson, A.J.; Kloo, L.; Brinck, T. Aqueous solvation and surface oxidation of the $\mathrm{cu}_{7}$ nanoparticle: Insights from theoretical modeling. J. Phys. Chem. C 2016, 120, 1977-1988. [CrossRef]

59. Murray, J.; Lane, P.; Clark, T.; Riley, K.; Politzer, P. $\sigma$-Holes, $\pi$-holes and electrostatically-driven interactions. J. Mol. Model. 2012, 18, 541-548. [CrossRef] [PubMed]

60. Xiao, L.; Wang, L. Structures of platinum clusters: Planar or spherical? J. Phys. Chem. A 2004, 108, 8605-8614. [CrossRef]

61. Zhang, W.; Xiao, L.; Hirata, Y.; Pawluk, T.; Wang, L. The simple cubic structure of Ir clusters and the element effect on cluster structures. Chem. Phys. Lett. 2004, 383, 67-71. [CrossRef]

62. Du, J.; Sun, X.; Chen, J.; Jiang, G. A Theoretical study on small iridium clusters: Structural evolution, electronic and magnetic properties, and reactivity predictors. J. Phys. Chem. A 2010, 114, 12825-12833. [CrossRef] [PubMed]

63. Reiher, M.; Salomon, O.; Hess, B.A. Reparameterization of hybrid functionals based on energy differences of states of different multiplicity. Theor. Chem. Acc. 2001, 107, 48-55. [CrossRef]

64. Slimani, A.; Yu, X.; Muraoka, A.; Boukheddaden, K.; Yamashita, K. Reparametrization approach of DFT functionals based on the equilibrium temperature of spin-crossover compounds. J. Phys. Chem. A 2014, 118, 9005-9012. [CrossRef] [PubMed]

65. Young, D.C. Spin Contamination. In Computational Chemistry; John Wiley \& Sons, Inc.: San Francisco, CA, USA, 2001; pp. 227-230.

66. Chaves, A.S.; Piotrowski, M.J.; Da Silva, J.L.F. Evolution of the structural, energetic, and electronic properties of the $3 \mathrm{~d}, 4 \mathrm{~d}$, and $5 \mathrm{~d}$ transition-metal clusters $\left(30 \mathrm{TM}_{\mathrm{n}}\right.$ systems for $\left.\mathrm{n}=2-15\right)$ : A density functional theory investigation. Phys. Chem. Chem. Phys. 2017, 19, 15484-15502. [CrossRef] [PubMed]

67. Da Silva, J.L.F.; Piotrowski, M.J.; Aguilera-Granja, F. Hybrid density functional study of small $\mathrm{Rh}_{\mathrm{n}} \mathrm{n}=2-15$ clusters. Phys. Rev. B 2012, 86, 125430. [CrossRef] 
68. Yamaguchi, K.; Jensen, F.; Dorigo, A.; Houk, K.N. A spin correction procedure for unrestricted Hartree-Fock and Møller-Plesset wavefunctions for singlet diradicals and polyradicals. Chem. Phys. Lett. 1988, 149, 537-542. [CrossRef]

69. Yamaguchi, K.; Okumura, M.; Mori, W.; Maki, J.; Takada, K.; Noro, T.; Tanaka, K. Comparison between spin restricted and unrestricted post-Hartree-Fock calculations of effective exchange integrals in Ising and Heisenberg models. Chem. Phys. Lett. 1993, 210, 201-210. [CrossRef]

70. Yasuda, N.; Kitagawa, Y.; Hatake, H.; Saito, T.; Kataoka, Y.; Matsui, T.; Kawakami, T.; Yamanaka, S.; Okumura, M.; Yamaguchi, K. Approximate spin projection for geometry optimization of biradical systems: Case studies of through-space and through-bond systems. In Quantum Systems in Chemistry and Physics; Springer: Dordrecht, The Netherlands, 2012; pp. 345-359.

71. Heisenberg, W. Zur Theorie des Ferromagnetismus. Z. Phys. 1928, 49, 619-636. [CrossRef]

72. Kambe, K. Paramagnetic susceptibilities of some polynuclear complex salts. J. Phys. Soc. Jpn. 1950, 5, 48-51. [CrossRef]

(C) 2017 by the authors. Licensee MDPI, Basel, Switzerland. This article is an open access article distributed under the terms and conditions of the Creative Commons Attribution (CC BY) license (http:/ / creativecommons.org/licenses/by/4.0/). 